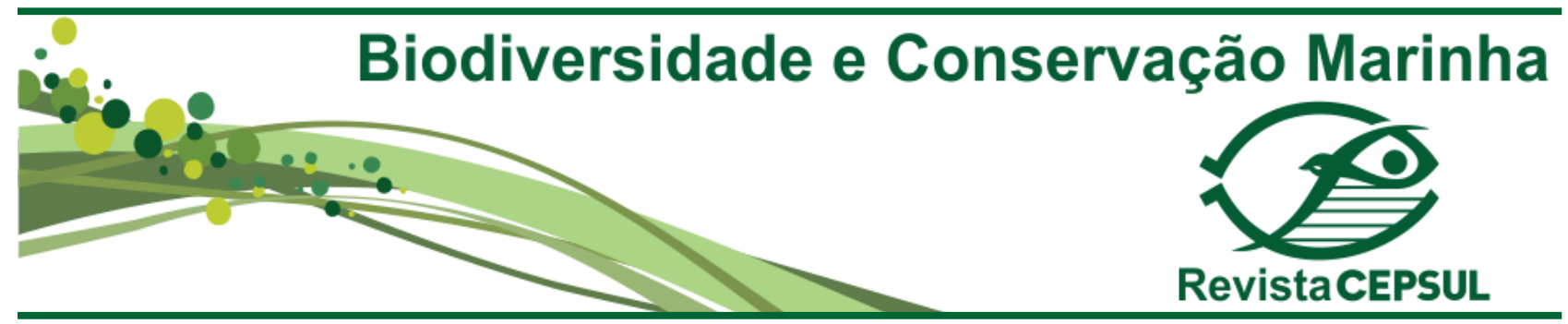

\title{
Observações histológicas em glândulas oviducais do tubarão-azul, Prionace glauca Linnaeus (1758), capturado pela frota espinheleira-de-superfície sediada em Itajaí - SC
}

\author{
Jorge EduARdo Kotas ${ }^{1}$ \& David Rivero TAMES ${ }^{2}$ \\ ${ }^{1}$ Centro Nacional de Pesquisa e Conservação da Biodiversidade Marinha do Sudeste e Sul - ICMBio/CEPSUL, Avenida Carlos Ely \\ Castro, 195, CEP - 88301-445, Centro, Itajaí, SC, Brasil, jorge.kotas@icmbio.gov.br; \\ ${ }^{2}$ Laboratório de Histologia, Universidade do Vale do Itajaí - UNIVALI, Rua Uruguai, 458, CEP - 88302-901, Centro, Itajaí, SC, \\ Brasil,dtames@univali.br.
}

\section{Submetido em: 27/o4/2015; Aceito em: 04/o3/2021; Publicado em: 10/o5/2021}

DOI 10.370o2/revistacepsul.vol1o.548e2021oo3

\begin{abstract}
Resumo. O presente estudo conheceu em detalhes a estrutura e função da glândula oviducal do tubarão-azul, Prionace glauca, de fundamental importância na reprodução e perpetuação da espécie no Atlântico Sul, melhorando o conhecimento da biologia da espécie. Foram aplicadas técnicas histológicas em glândulas oviducais de duas fêmeas adultas no estágio $3 \mathrm{e}$ de três no estágio 5, segundo os critérios de Colonello. Cortes histológicos longitudinais de $7 \mu \mathrm{m}$ de espessura inicialmente foram corados com hematoxilina e eosina. Posteriormente, testes histoquímicos também foram aplicados, utilizando as colorações Ácido PeriódicoSchiff (PAS) e o Azul Alciano (AB). Quatro zonas foram identificadas: Club, Papillary, Baffle e Terminal. Na zona Baffle foi observada uma intensa atividade secretora de colágeno da cápsula, sinal de fase ovulatória. Na zona Terminal, foi observado armazenamento de esperma. Os testes histoquímicos indicaram reação positiva com o corante PAS nas regiões epiteliais e glandulares das quatro zonas, bem como nos agrupamentos de espermatozoides, indicativo da presença de glicosaminoglicanos neutros. Por outro lado, a reação foi positiva com o corante $\mathrm{AB}$ apenas nas regiões glandulares das zonas Club e Papillary, nos espermatozoides, bem como nas secreções dentro dos cistos que os armazenam, indicativo de atividade secretora de glicosaminoglicanos ácidos (sulfatados e não sulfatados). Com os resultados obtidos, conforme constatado também em outros estudos, observou-se que a glândula oviducal é extremamente especializada em termos fisiológicos, pois além da sua capacidade de armazenamento de esperma por longos períodos, apresenta uma elevada atividade secretora e que, em conjunto com os movimentos ciliares na sua região luminal, propiciam a formação da gelatina e da cobertura terciária protetora do ovo, sendo este posteriormente depositado no interior do útero, para dar início à fase gestacional.
\end{abstract}

Palavras-chave: armazenamento de espermas, histoquímica, elasmobrânquios. 


\begin{abstract}
Histological observations in oviducal glands of the blue shark, Prionace glauca Linnaeus (17558), caught by the surface longline fleet based in Itajaí, Santa Catarina State, Brazil. The study aimed at understanding the structure and function of the oviducal gland of the blue shark, Prionace glauca, extremely important for its reproductive cycle and conservation in the South Atlantic. Histological technics were tested in oviducal glands of five adult females, i.e., two in stage 3 and three in stage 5 , following the criteria of Colonello. Longitudinal sections of $7 \mu \mathrm{m}$ were sliced and dyed with hematoxiline and eosine. Afterwards, histochemical tests were also applied with the dyes Periodic Acid-Schiff reaction (PAS) and Alcian Blue (AB). Four zones were detected: Club, Papillary, Baffle and Terminal. The Baffle zone showed an intensive collagen secretory activity, a sign of ovulation. In the Terminal zone sperm storage was observed. The histochemical tests showed positive reaction with PAS in the epithelial and glandular regions of the four zones, as well as in the sperm, indicating the presence of neutral glycosaminglicans. Conversely there was only positive reaction with $\mathrm{AB}$ in the glandular regions of the Club and Papillary zones, sperm, as well secretions within the cists that storage it, indicating secretory activity of acid glycosaminglicans (sulphated and non-sulphated). The histological technics showed that the physiology of the oviducal gland - as known from other studies - is highly specialized, storing sperm for long periods, also having high secretory capacity. Together with its ciliary movements in the lumen, it allows the production of jelly and collagen to protect the egg and deposit it in the womb, as to begin pregnancy.
\end{abstract}

Keywords: sperm storage, histochemistry, elasmobranch.

\section{Introdução}

Em quase todas as espécies de Chondrichthyes, independente do modo reprodutivo, os ovos são inicialmente envoltos por um revestimento (envelope terciário) (Hamlett et al., 1998a). Este revestimento é produzido por uma glândula especializada denominada de glândula oviducal (GO), também chamada glândula nidamentar ou glândula da casca (Koob \& Callard, 1991).

As GOs são estruturas especializadas na região anterior do oviduto na maioria dos Chondrichthyes (Knight et al., 1993, Prasad, 1945) e são de fundamental importância para a reprodução nos condrícteos, já que nessas estruturas ocorre, além da ovulação, também o armazenamento do esperma, possibilitando desta forma a fertilização em um momento adequado. As raias elétricas dos gêneros Narcine e Tetronarce são os únicos Chondrichthyes que não apresentam glândulas oviducais (Prasad, 1945).

A maioria da literatura publicada sobre a estrutura e função da GO foi relativa ao pequeno cação-gato Scyliorhinus canícula Linnaeus (1758) ovíparo (Metten, 1939, Thread- gold, 1957, Rusaouën, 1976, Knight et al., 1996) e descrições morfológicas das GOs de quimeras (Holocephali) foram publicadas por Dean (1895, 1906, 1912), Prasad (1948) e Stanley (1963), mas sem análises histoquímicas. Smith et al. (2004) trabalharam com a histologia e histoquímica da glândula oviducal da quimera Callorhynchus milii Bory de Saint-Vincent (1823). Rangel et al. (2015) por meio de microscopia eletrônica e ótica, realizaram estudos morfológicos da GO do tubarão-azul P. glauca, porém sem uso de métodos histoquímicos.

A variação no tamanho da GO está diretamente relacionada com o ciclo reprodutivo, acompanhando o desenvolvimento folicular e atingindo tamanhos máximos um pouco antes da ovulação, e diminuindo posteriormente (e.g. Hamlett, 1999, Serra-Pereira et al., 2011).

As GOs são genericamente compostas por quatro zonas, caracterizadas pela morfologia de suas lamelas e funções secretoras, o que possibilita a comparação entre as espécies, independente do modo reprodutivo (Hamlett et al., 1999a): Club, Papillary, Baffle e Terminal. As variações entre as espécies existem em nível morfológico, mas a organização básica das qua- 
tro zonas é de certa forma mantida.

As zonas Club e Papillary são responsáveis pela produção das diversas coberturas gelatinosas que rodeiam o ovo. Essa gelatina funciona como uma estrutura para suportar hidrodinamicamente o ovo e embriões em desenvolvimento (Koob \& Straus, 1998). Foi sugerido que a gelatina produzida pela GO tem um papel crítico para o desenvolvimento do embrião, pelo menos nos estágios iniciais. A gelatina suporta o embrião durante o período frágil da embriogênese, quando este apresenta filamentos branquiais externos. A gelatina é progressivamente liquefeita à medida que o embrião cresce (Hamlett et al., 1998a, Koob \& Straus, 1998). Não há evidências de que as camadas de gelatina sejam nutritivas para o embrião (Koob \& Straus, 1998).

A zona Baffle é responsável pela secreção dos diversos tipos de revestimentos ou envelopes terciários encontradas nos Chondrichthyes, que podem ter a forma de uma simples membrana em espécies vivíparas ou de uma cápsula dura em espécies ovíparas (Hamlett et al., 1998a, Knight et al., 1996). Existe o caso da raia-de-esporão-pintada, Urobatis jamaicensis Cuvier (1816), que pelo fato de não produzir envoltório sobre o ovo, não apresenta zona Baffle (Hamlett et al., 1998b, Hamlett et al., 2005).

Finalmente, a zona Terminal armazena o esperma, produz finos pelos que decoram a parte externa da cápsula do ovo de algumas espécies ovíparas e tem também um papel lubrificante (Metten, 1939, Prasad, 1945, Hamlett et al., 1998a).

A morfologia interna da glândula oviducal do tubarão-azul, $P$. glauca é semelhante a de outros elasmobrânquios, à exceção do tubarão-peregrino, Cetorhinus maximus Gunnerus (1765), que não apresenta divisões evidentes na GO e secreções de envoltórios sobre os embriões (Mattews, 1950, Hamlett et al., 1998a, 2002a, 2002b, Storrie et al., 2008, Moura et al., 2011).

$\mathrm{O}$ armazenamento do esperma em fêmeas, embora ocorra em diversos grupos zoológicos como insetos, moluscos, peixes, aves, rép- teis e mamíferos, é um fenômeno ainda pouco conhecido, e que abre possibilidades para pesquisas futuras (Holt \& Lloyd, 2010). O esperma é retido em estruturas especializadas pelo menos até ao momento da ovulação, momento em que o esperma se aproxima do lúmen da glândula próximo do local de passagem dos óvulos (Pratt, 1993, Hamlett et al., 1998a, SerraPereira et al., 2011). Vários répteis, e.g. Alligator mississipiensis Birkhead \& Møller (1993), Crotalus durissus terrificus Almeida-Santos \& Salomão (1997), apresentam túbulos de fundo cego para essa função. A cobra asiática, Acrochordus javanicus Hornstedt (1787), possui a capacidade de armazenar seu esperma por um período de até sete anos (Magnusson, 1979). O avestruz, Struthio camelus Linnaeus (1758), consegue armazenar o esperma por até 4 semanas (Malecki et al., 2004). Os mamíferos possuem o hábito de armazenar os espermatozoides na vagina, cérvix, útero ou oviduto, e no caso do morcego-marrom, Myotis lucifugus Le Conte (1831), uma coorte de espermatozoides formam complexas e íntimas associações com as células epiteliais uterinas e oviducais, especialmente na junção útero-tubal, podendo permanecer armazenados por um período de até seis meses (Racey et al., 1987). Os peixes como os Poeciliidae e Sebastidae por sua vez desenvolveram inúmeros mecanismos, como o direto armazenamento do esperma dentro dos folículos ovarianos. No caso do peixe-de-pedra de boca azul, Helicolenus dactylopterus Delaroche (1809), o esperma pode ficar armazenado no ovário por um período de até dez meses (Vila et al., 2007).

O armazenamento de esperma na zona Terminal é um fenômeno também comum em Chondrichthyes (e.g. Metten, 1939, Prasad, 1944, 1945, Pratt, 1993, Knight et al., 1996, Hamlett et al., 1998a, 2005, Storrie et al., 2001, 2008, Smith et al., 2004, Moura et al., 2011). Dependendo da espécie, o esperma pode ser armazenado por curtos ou longos períodos, que podem ir de meses ou até mesmo de mais de um ano antes da fertilização (Smith et al., 2004, Hamlett et al., 2005, Storrie et al., 2008). Por meio dessa estrutura as chances de ocorrer uma inseminação bem-sucedida au- 
mentam consideravelmente (Pratt, 1993). No caso de algumas espécies, como o tubarãomartelo-entalhado, Sphyrna lewini Griffith \& Smith (1834), os túbulos secretores que recebem o esperma são especializados e funcionam como verdadeiras vesículas seminais (McMillan, 2007). Nos tubarões, o armazenamento geralmente ocorre nas GOs, mas também pode ocorrer em outras partes do aparelho reprodutivo (Hamlet et al., 2002a). No caçãogato Scyliorhinus retifer Garman (1881), o esperma pode ficar armazenado além de dois anos (Castro et al., 1988).

Portanto, estudos com métodos histoquímicos envolvendo outras espécies de elasmobrânquios são necessários, ampliando o conhecimento de sua histofisiologia reprodutiva, para análises comparativas, tanto para melhor conhecimento da biologia da espécie, como de conservação. Sendo assim, o presente estudo teve como objetivo descrever e comparar a estrutura e função da GO nas fêmeas de P. glau$c a$, por meio da aplicação de técnicas histológicas de rotina (HE) e histoquímicas (PAS e Alcian Blue), sendo esta considerada uma espécie de alto interesse econômico, pois é a principal espécie de tubarão capturada pelas frotas industriais de espinhel-de-superfície operantes no Atlântico Sul.

\section{Material e métodos}

Os exemplares de P. glauca foram cap- turados por meio de espinhéis-de-superfície, e amostrados a bordo de uma embarcação de pesquisa (amostras 1, 2 e 3) e outra comercial (amostras 4 e 5), operantes na Zona Econômica Exclusiva do Sul do Brasil (Tabela 1).

A embarcação comercial utilizou 1500 anzóis/lance, sendo os anzóis do tipo "J" 13/o, sem estropo de aço em todos os anzóis, sendo a isca a sardinha e a lula. Neste caso não foi utilizado Lightstick e o comprimento do espinhel ficou em 28 milhas náuticas. Já no caso do espinhel utilizado pela embarcação de pesquisa, as informações técnicas do petrecho de pesca podem ser encontradas em Sales et al. (2010). Como em ambos os cruzeiros o principal interesse dos pesquisadores e observadores de bordo foram a seletividade de anzóis para as espécies de peixes pelágicos e as capturas de tartarugas, apenas cinco amostras da espécie foram obtidas. Todos os exemplares chegaram vivos ao convés da embarcação, onde foram imediatamente sacrificados pelos pescadores, por meio de degola e inserção de um arame de aço inoxidável no arco neural do tubarão (perda de consciência - método mecânico). Esse procedimento é utilizado de praxe pelos pescadores, baseado em suas experiências na manipulação das capturas, com o objetivo de evitar possíveis acidentes no convés, ocasionados por mordidas desses animais, bem como minimizando o sofrimento dos animais capturados (Resolução Normativa $\mathrm{n}^{0} 25$, de 29 de setembro de 2015, publicado no Diário Oficial da União, Ministé-

Tabela 1. Informações sobre as capturas dos exemplares de $P$. glauca que foram utilizados para a realização dos cortes histológicos nas glândulas oviducais.

\begin{tabular}{cccccc}
\hline $\begin{array}{c}\text { Código da } \\
\text { Amostra }\end{array}$ & $\begin{array}{c}\text { Data da captura e } \\
\text { extração das GOs }\end{array}$ & \multicolumn{2}{c}{ Local da captura } & $\begin{array}{c}\text { Temperatura } \\
\text { La água de } \\
\text { superfície }{ }^{\circ} \mathbf{C}\end{array}$ & $\begin{array}{c}\text { Profundidade } \\
\text { local (m) }\end{array}$ \\
\hline 1 & $01 / 12 / 2004$ & $28^{\circ} 36^{\prime} 468^{\prime \prime}$ & $46^{\circ} 04^{\prime} 937^{\prime \prime}$ & 22,7 & 2588 \\
2 & $23 / 01 / 2008$ & $27^{\circ} 37^{\prime} 610^{\prime \prime}$ & $46^{\circ} 46^{\prime} 315^{\prime \prime}$ & 24,8 & 1114 \\
3 & $24 / 01 / 2008$ & $27^{\circ} 01^{\prime} 291^{\prime \prime}$ & $46^{\circ} 15^{\prime} 777^{\prime \prime}$ & 24,2 & 1021 \\
4 & $07 / 12 / 2015$ & $27^{\circ} 54^{\prime} 465^{\prime \prime}$ & $48^{\circ} 07^{\prime} 211^{\prime \prime}$ & 22,2 & 91 \\
\hline 5 & $07 / 12 / 2015$ & $27^{\circ} 54^{\prime} 465^{\prime \prime}$ & $48^{\circ} 07^{\prime} 211^{\prime \prime}$ & 22,2 & 91 \\
\hline
\end{tabular}


rio da Ciência, Tecnologia e Inovação/Conselho Nacional de Controle de Experimentação Animal; Guia Brasileiro de Boas Práticas para a Eutanásia de Animais - Conceitos e Procedimentos Recomendados, 2013). Após o sacrifício das fêmeas, foram obtidas as medidas de comprimento total (CT - da ponta do focinho até a extremidade superior da nadadeira caudal, com o animal alinhado ao longo do eixo do corpo), comprimento furcal ( $\mathrm{CF}$ - da ponta do focinho até a furca caudal). Essas medidas de comprimento foram registradas com uma trena em $\mathrm{cm}$. Para a extração do aparelho reprodutor foi realizado um corte longitudinal na região abdominal, desde a abertura cloacal até a altura das duas nadadeiras peitorais. $\mathrm{O}$ trato digestivo foi previamente removido, para melhor visualização e medição (Figura 1). A seguir o estágio reprodutivo foi avaliado segundo os critérios macroscópicos para fêmeas adultas vivíparas de Colonello et al. (2011). Após a avaliação do estágio reprodutivo, o aparelho reprodutor foi extraído da fêmea e estendido sobre uma mesa, onde foram medidas com uma trena a largura e o comprimento do ovário e dos úteros em $\mathrm{cm}$.
No caso das GOs foi obtida com um paquímetro apenas a largura em mm. As duas GOs foram extraídas com bisturi e tesoura cirúrgica, sendo fixadas a bordo em formalina a $10 \%$ e posteriormente, chegando em terra, conservadas em álcool absoluto a $70 \%$ durante alguns dias até o momento do corte (Figura 2). Após a decapitação e evisceração do animal a bordo, foi obtido com uma trena o comprimento da carcaça (CC) em cm, segundo Amorim et al. (1997). Os tubarões não foram pesados, por conta da movimentação da embarcação, o que interferia na precisão dessa medida. As medidas obtidas com trena foram em $\mathrm{cm}$. As obtidas com paquímetro foram em $\mathrm{mm}$.

No laboratório de histologia cortes longitudinais (ou sagitais), de aproximadamente 5 mm de espessura, com facas descartáveis de microtomia, foram realizados na região mediana das GOs obtidas (Figura 2). As peças foram posteriormente submetidas à desidratação progressiva em banhos com álcool etílico de concentração crescente (70\%, 90\% e 100\%), trocados a cada oito horas. A seguir foram diafanizados com três banhos de trinta minutos, cada

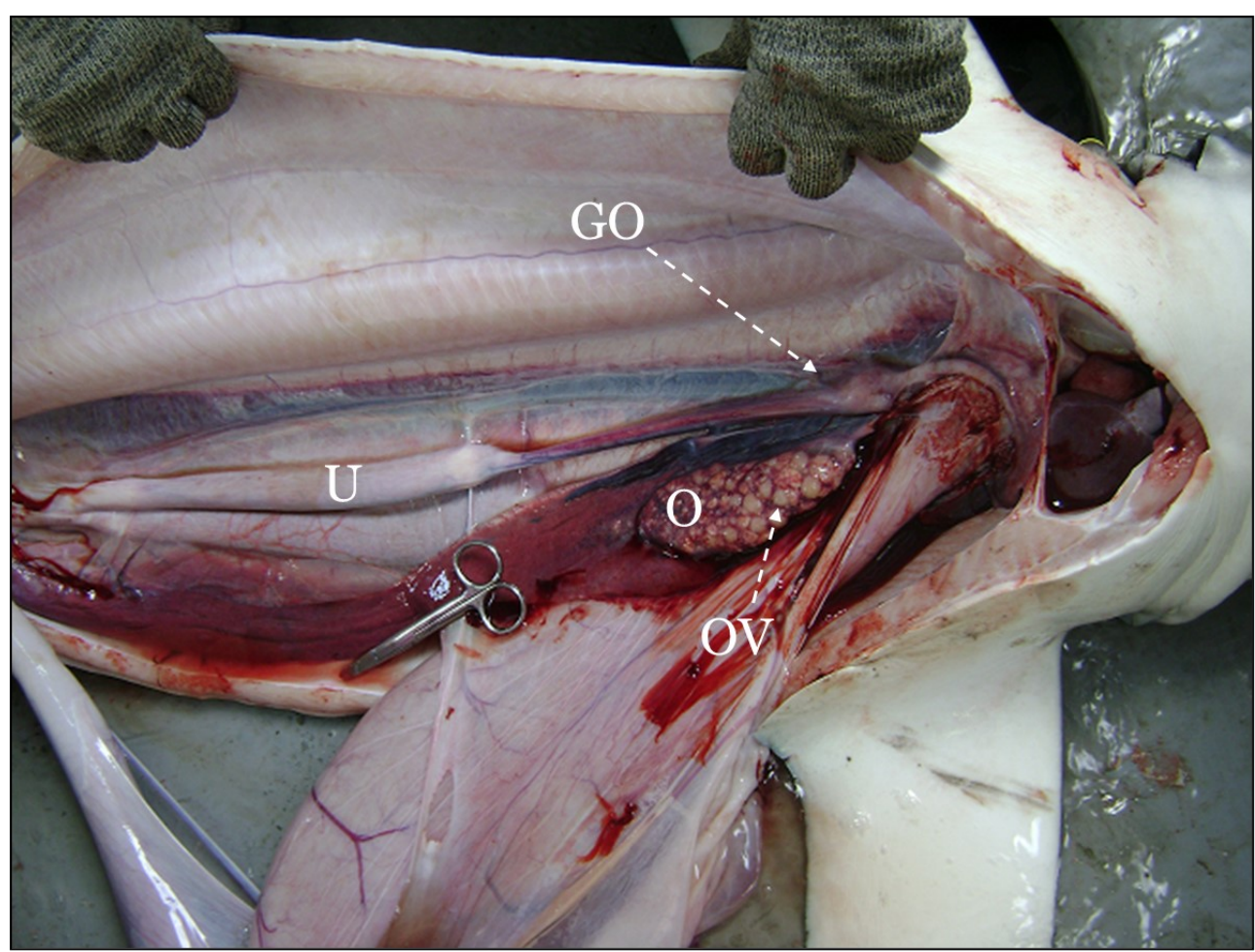

Figura 1. Aparelho reprodutor de P. glauca. Estágio reprodutivo - adulta 3 não grávida. Cruzeiro espinhel de superfície (NPq. Soloncy Moura). O - Ovário; U Útero; GO - Glândula oviducal; OV - Ovócitos maturos. 


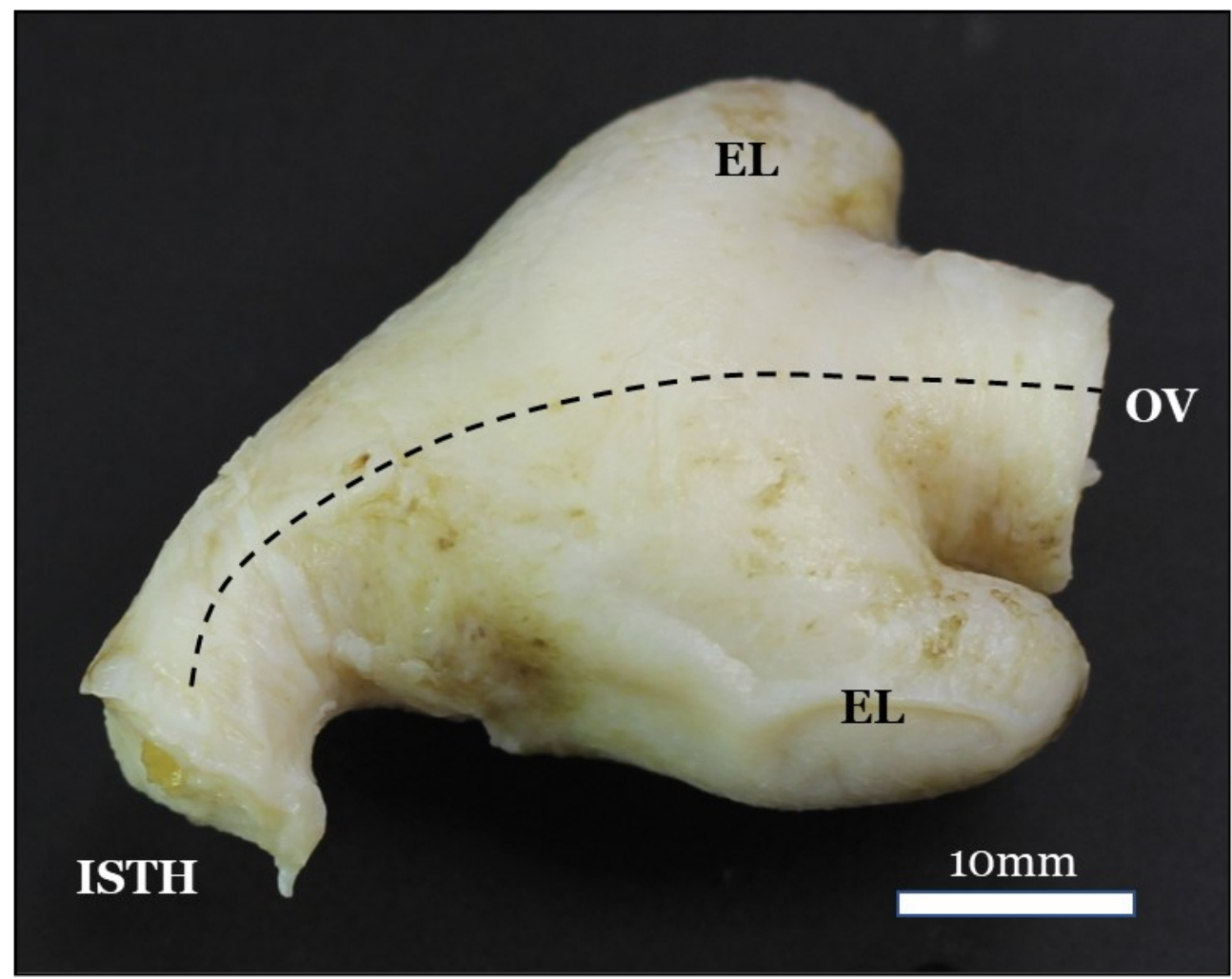

Figura 2. Anatomia externa da glândula oviducal in situ, mostrando as extensões laterais (EL) do lúmen da glândula e que dão a forma de "chifre de cabra". As posições do oviduto (OV) e do Isthmus (ISTH) são indicadas. A linha pontilhada indica a posição da dissecção. A GO já está fixada. Foto: Jorge Eduardo Kotas.

um, em xilol. Finalmente efetuou-se a inclusão em parafina liquida dentro de uma estufa a $60^{\circ} \mathrm{C}$. Após o esfriamento da parafina, os blocos com tecidos foram cortados em um micrótomo Bright 5040, obtendo-se cortes com $7 \mu \mathrm{m}$ de espessura, o que possibilitou o ganho de definição e clareza nas imagens. Finalmente, coraram-se os cortes com hematoxilina de Harris e eosina amarela (0,25\%), seguindo o protocolo descrito em Bancroft et al. (1996).

Como as diferentes zonas da GO apresentam afinidade com determinados corantes como o Ácido Periódico-Schiff (PAS, McManus, 1946) e o Azul Alciano (AB, Haddock, 1948), relacionados com as suas atividades secretoras (Hamlett et al., 1998a), testes histoquímicos foram também aplicados nos cortes das GOs de $P$. glauca, com o objetivo de se detectar a presença de glicosaminoglicanos (mucopolissacarídeos) nessas estruturas (Bancroft et al., 1996). No caso da reação ser PAS-positiva, o corte histológico exibe a coloração vermelha (Stoward, 1967), detectando-se a presença de glicosaminoglicanos neutros. Já no caso da reação ser AB-positiva, o corte apresenta coloração azulada, indicando a presença de glicosaminoglicanos ácidos sulfatados e não sulfatados. As colorações PAS e AB foram efetuadas em separado nos cortes, com o fim de caracterizar melhor a reação positiva ou negativa para cada reagente. Desta forma as diferentes regiões foram avaliadas em maior detalhe.

O material histológico utilizado no presente estudo foi extraído das GOs de duas fêmeas adultas no estágio 3 (maturas não grávidas) e de três fêmeas adultas no estágio 5 (maturas grávidas) (Figura 1) e cujas características constam na Tabela 2.

Os cortes foram analisados em microscópio de luz transmitida, e documentados com fotomicrografias obtidas com fotomicroscópio óptico binocular OLYMPUS BX50. As análises das imagens coradas com HE foram feitas por meio do software Image Pro Plus. Por sua vez, na histoquímica as imagens foram captadas com o software HD digital microscope imager 


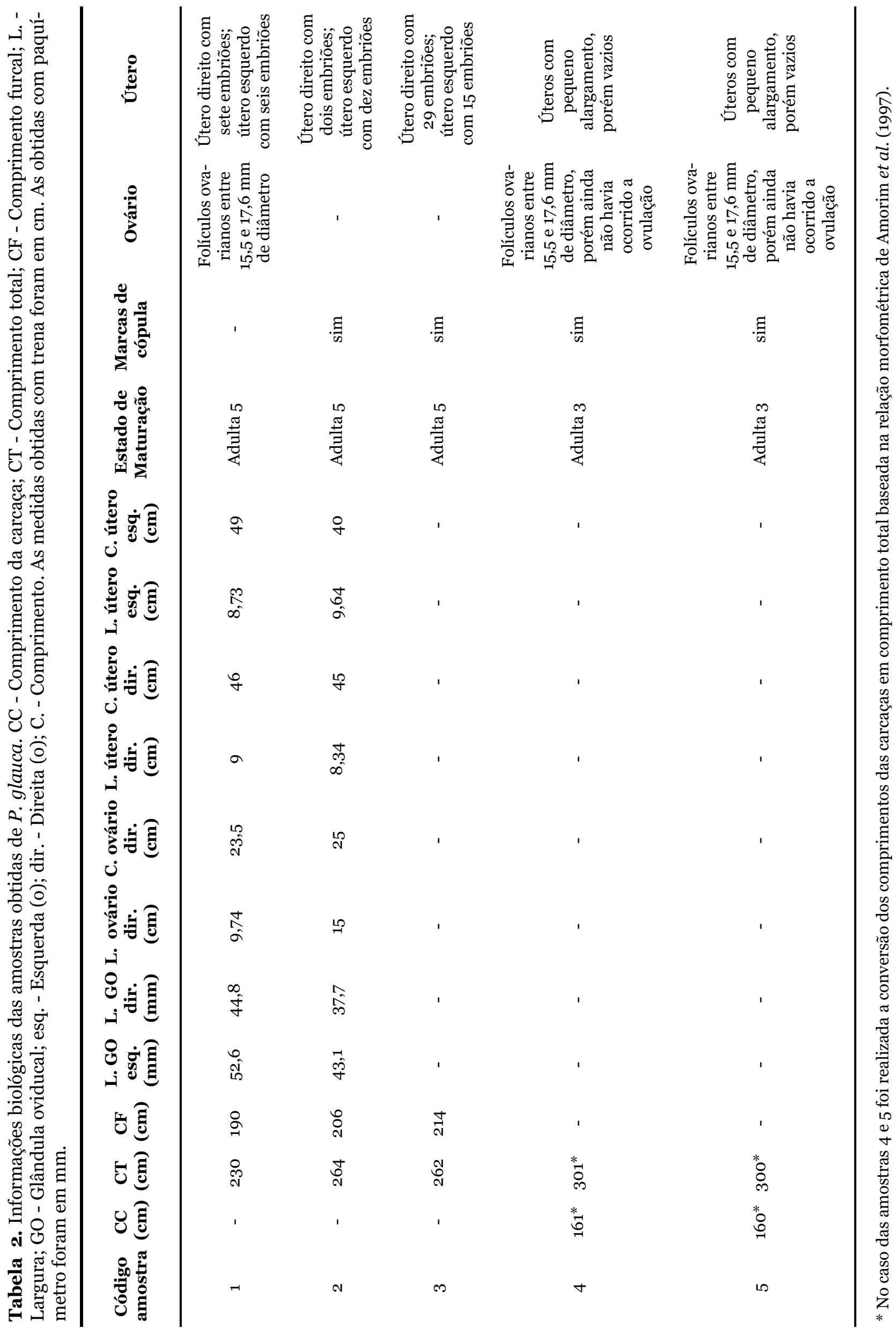




\section{da CELESTRON.}

\section{Resultados}

As GOs de fêmeas maturas de P. glauca (Figura 1, neste caso adulta 3, ou seja, matura não grávida, pois ainda não havia ocorrido a ovulação e o útero se encontrava vazio) apresentam uma morfologia externa peculiar, de formato aproximadamente triangular invertido e com duas protuberâncias semelhantes a pequenos chifres (Figura 2). Os cortes sagitais evidenciam diferentes zonas na glândula e que são mais bem evidenciados com a utilização de um corante histológico específico, como é o caso da Hematoxilina-Eosina (HE) (Figura 3). Nesta última figura, embora tenha havido todo um esforço manual de realizar o corte passando o mais próximo do eixo central do lúmen da glândula, a abertura para o oviduto não apareceu. Possivelmente houve um desvio no corte, ou à direita ou à esquerda do eixo central do lúmen, e que gerou a não visualização da abertura do oviduto. No entanto, foi possível observar a localização das quatro zonas secretoras da
GO. A seguir serão apresentados os resultados referentes a cada uma das zonas mencionadas. Como os cortes apresentados nos resultados foram relativos a fêmeas adultas em estágio 5 , não foi possível verificar diferenças histoquímicas e histológicas nas diferentes zonas da GO para as diferentes fases de desenvolvimento.

\section{Morfologia geral}

\section{Zona Club}

Na zona $C l u b$ as papilas são constituídas por um tecido conjuntivo frouxo, pobre em vasos sanguíneos e externamente revestido por epitélio cilíndrico simples ciliado (Figura 4A), caracterizado pela presença de uma camada única de células cilíndricas de vários tamanhos e cujos núcleos se apresentam no mesmo nível. Ocorrem cílios na região epitelial e nos túbulos glandulares dessa Zona (Figura 4B). As papilas da zona Club parecem menos organizadas, como reflexo do ângulo do corte na GO, à semelhança do que ocorreu na Figura 3.

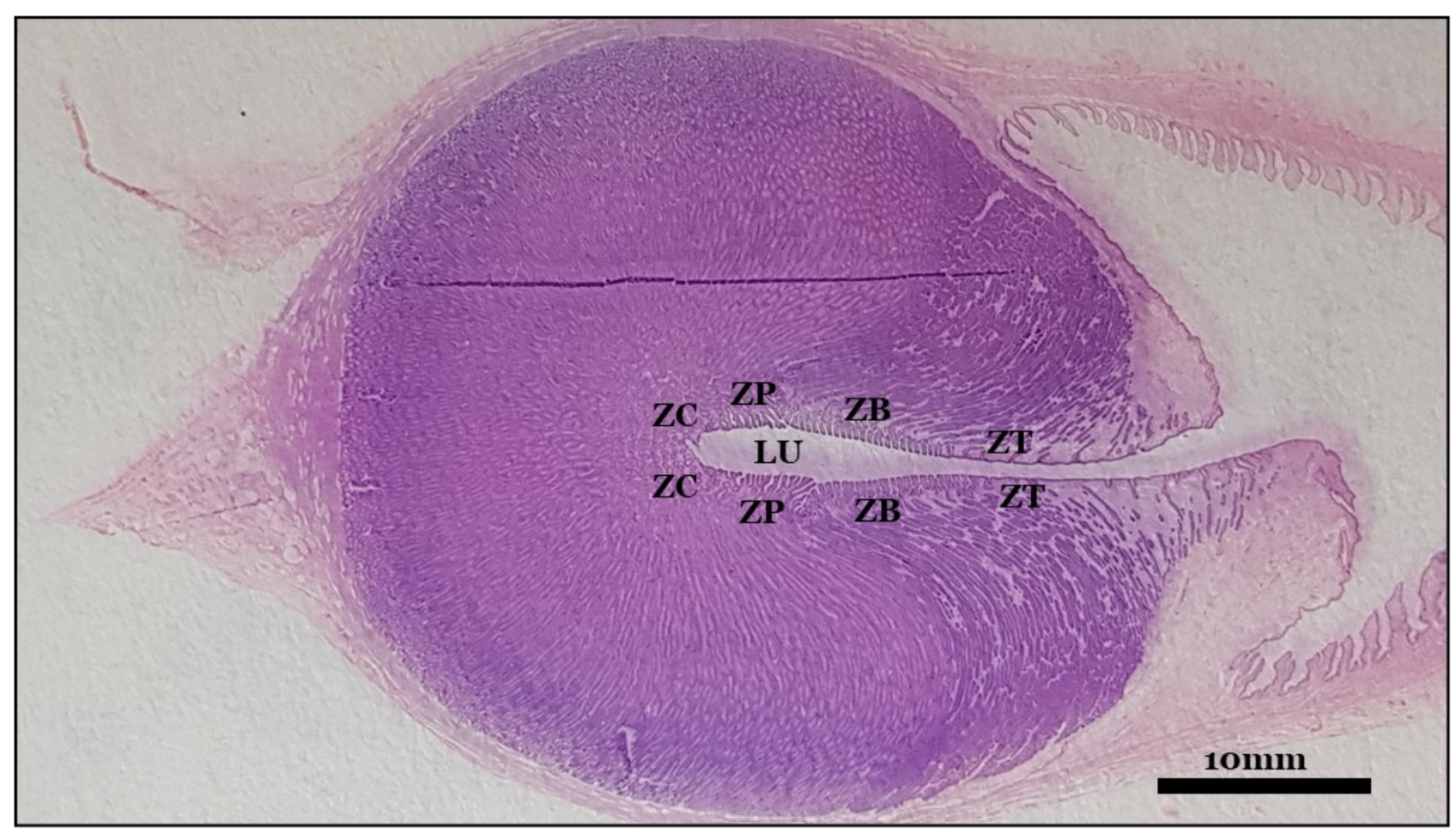

Figura 3. Prionace glauca. Secção longitudinal de uma GO (Estágio de maturação - adulta 5) mostrando a organização estrutural interna e as diferentes zonas. HE. ZC - Zona Club; ZP - Zona Papillary; ZB - Zona Baffle; ZT - Zona Terminal; LU - Lúmen. 

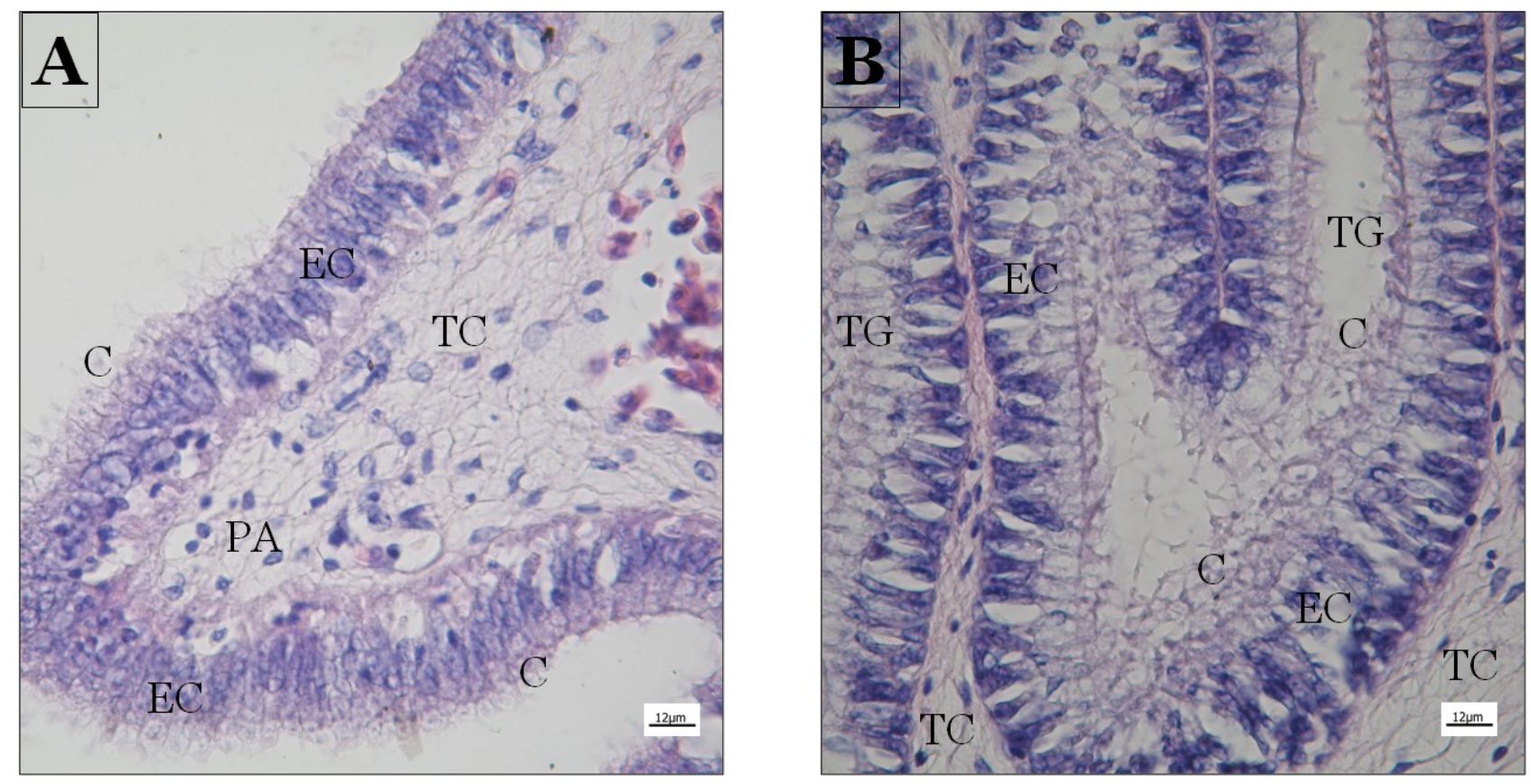

Figura 4. Corte longitudinal na Zona Club. Fêmea adulta 5. Coloração HE. Figura A. Imagem da papila e região epitelial ciliada. Figura B. Túbulos glandulares com epitélio ciliado. PA - Papila; TG - Túbulos glandulares; TC - Tecido conjuntivo pobre em vasos; C - os cílios do EC - epitélio cilíndrico simples.

\section{Zona Papillary}

Nesta zona as papilas já são mais definidas morfologicamente, mas a histologia é semelhante à zona Club, ou seja, internamente tecido conjuntivo frouxo, fracamente vasculari- zado, e externamente epitélio cilíndrico simples ciliado (Figura $5 \mathrm{~A}$ ). Ali também ocorrem as glândulas tubulares em grande quantidade e que são também revestidas com o mesmo tecido cilíndrico simples ciliado (Figura 5 B). Vasos
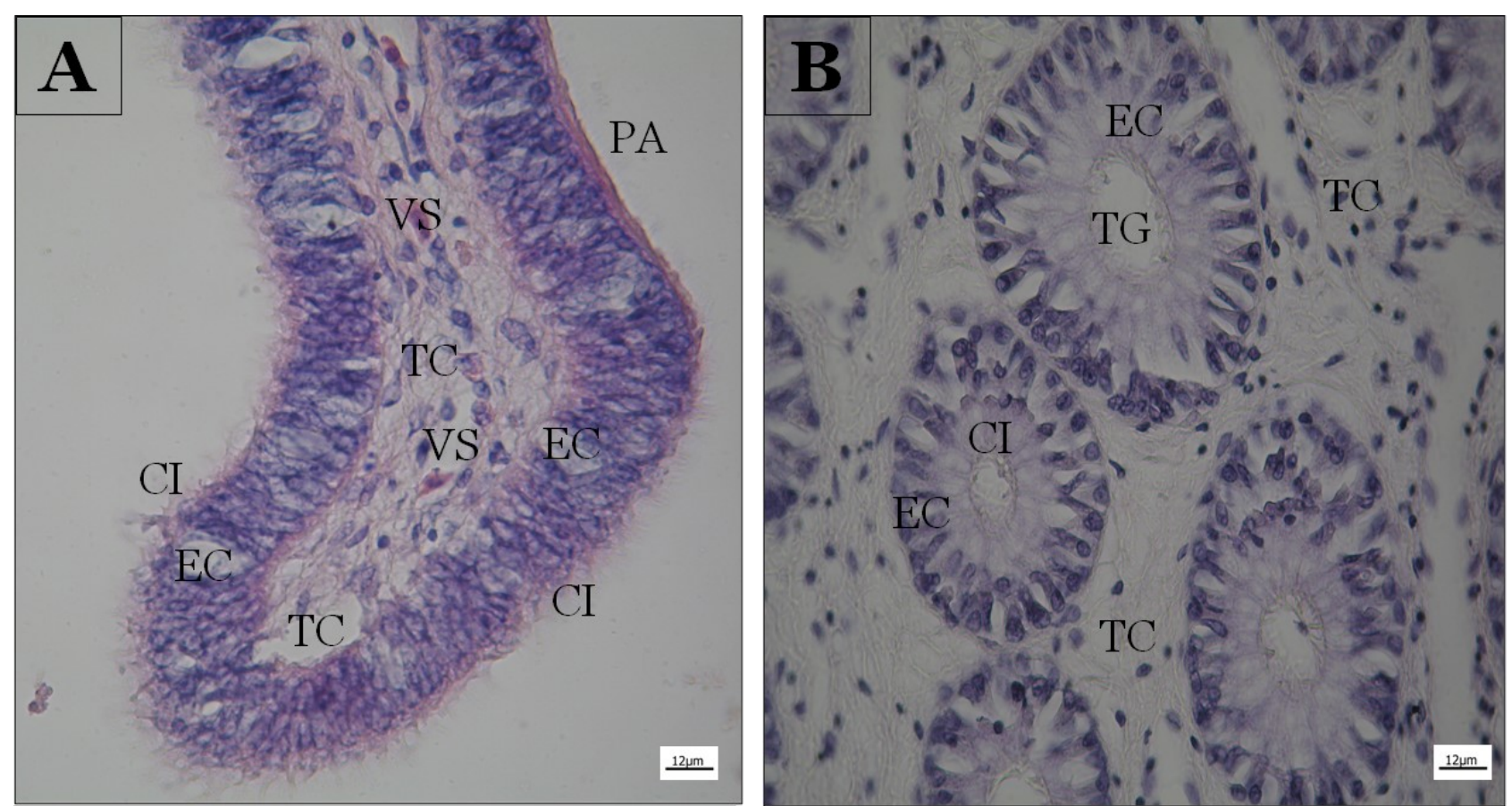

Figura 5. Corte longitudinal na Zona Papillary. Fêmea adulta 5. Coloração HE. Figura A. Papila com epitélio ciliado. Figura B. Túbulos glandulares com epitélio ciliado. TG - Túbulo glandular; EC - Epitélio cilíndrico simples ciliado; TC - Tecido conjuntivo fracamente vascularizado; VS - Vaso sanguíneo; CI - Cílios; PA - Papila da zona Papillary. 
sanguíneos são também visualizados no tecido conjuntivo frouxo.

\section{Zona Baffle}

O revestimento epitelial das lamelas apicais é do tipo cilíndrico simples ciliado, pois ocorre apenas uma camada de células, tendo cada célula, por definição, contato com a superfície (Figura 6A). Na zona Baffle há também a presença de glândulas tubulares que são revestidas desse epitélio cilíndrico simples ciliado,

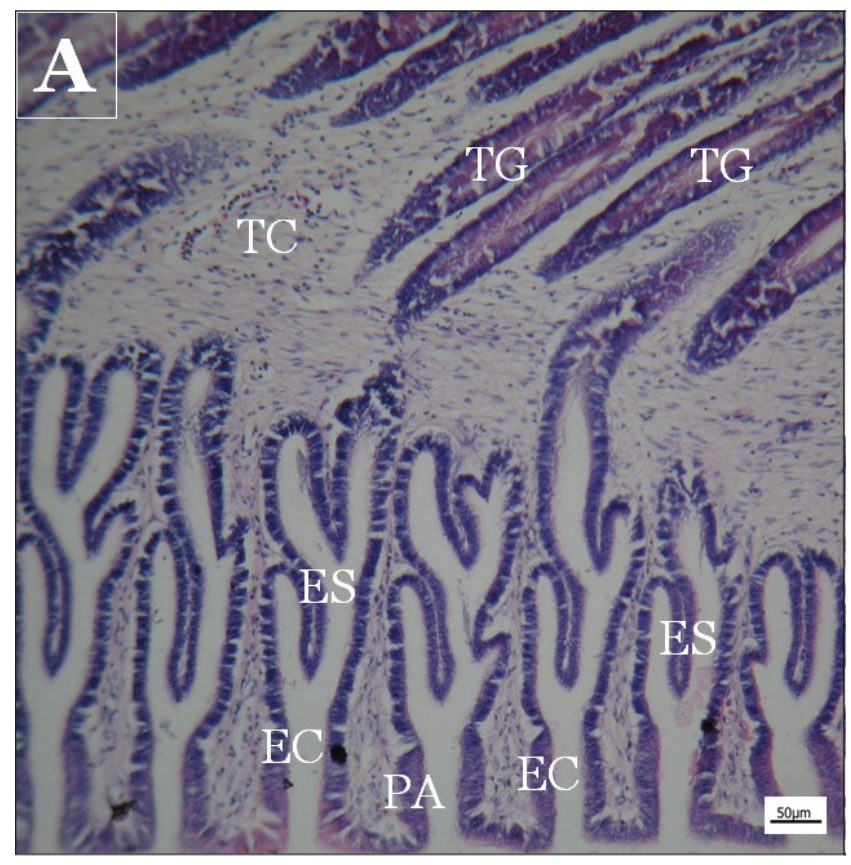

constituído por células granulares secretoras, intercaladas com células colunares ciliadas (Figura 6B). Cada túbulo é rodeado por uma membrana basal e tecido conjuntivo fracamente vascularizado. Não ocorre tecido muscular liso ou células mioepiteliais na parede desses túbulos (Figura 6B).

Nos cortes realizados em uma fêmea adulta 5 , foi observada intensa atividade secretora (Figura 6B), indicando que a fêmea matura de $P$. glauca em questão se apresentava na fase ovulatória.

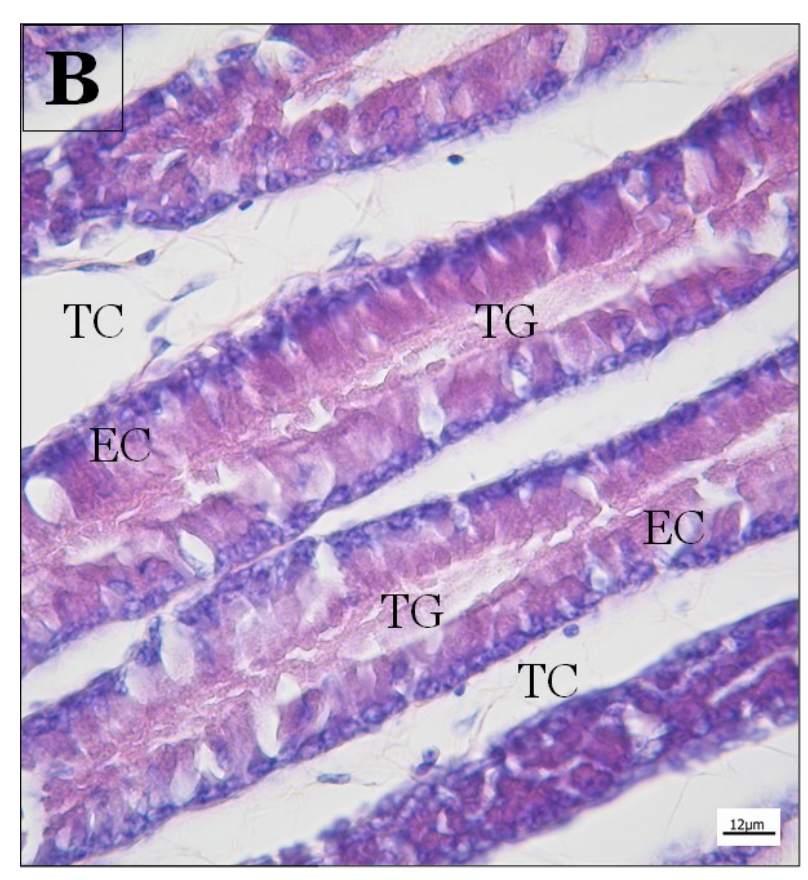

Figura 6. Corte longitudinal na Zona Baffle. Fêmea adulta 5. Coloração HE. Figura A. Papilas revestidas pelo epitélio ciliado. Figura B. Túbulos glandulares revestidos pelo epitélio ciliado no lúmen. TG - Túbulos glandulares; ES - Espinerete; EC - Epitélio cilíndrico simples ciliado; PA - Papilas da zona Baffle; TC - Tecido conjuntivo fracamente vascularizado.

\section{Zona Terminal}

O tecido epitelial na zona Terminal é do tipo simples colunar e ciliado, tanto na região luminal como glandular (Figura 7A). Tal epitélio foi observado em todas as zonas da GO de $P$. glauca. O preenchimento nessa zona também é de tecido conjuntivo fracamente vascularizado (Figuras 7A e 7B). Na fêmea adulta 5 foi observado esperma na zona Terminal. Este foi observado como uma massa de filamentos corada de roxo, localizada no lúmen dos túbulos glandulares (Figura $7 \mathrm{~B}$ ).

\section{Histoquímica}

\section{Ácido Periódico-Schiff (PAS)}

\section{Zona Club}

A reação com o corante PAS foi positiva apenas na região glandular, onde estão os túbulos secretores, havendo a coloração típica magenta, indicativo da presença de glicosaminoglicanos neutros (Figura 8A). No tecido conjuntivo fracamente vascularizado, a reação foi negativa. No epitélio cilíndrico simples ciliado da região glandular, as células PAS+ são granulo- 

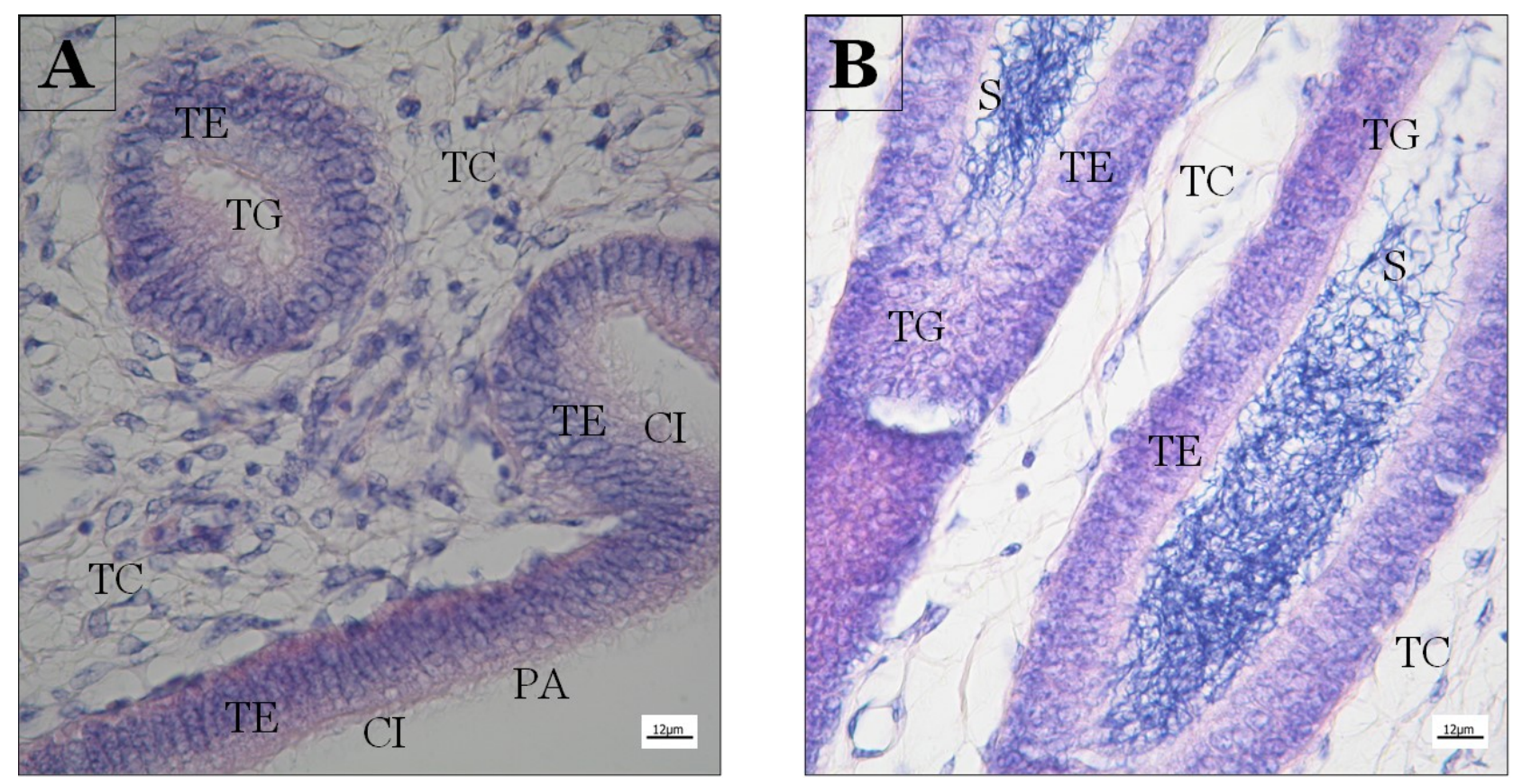

Figura 7. Corte longitudinal na Zona Terminal. Fêmea adulta 5. Coloração HE. Figura A. Região luminal revestida de epitélio ciliado e túbulo glandular também com células ciliadas no epitélio. Figura B. Túbulos glandulares revestidos de epitélio ciliar, armazenando "tufos" de esperma. S - Esperma; PA - Papila. TG - Túbulos glandulares; TC - Tecido conjuntivo fracamente vascularizado; TE - Tecido epitelial simples colunar e ciliado; CI - Cílios. O esperma, armazenado na zona Terminal, ocorre sob a forma de filamentos escuros no lúmen dos túbulos glandulares.

sas, com núcleos grandes basais, cheias de vesículas e possuem cílios em suas extremidades. No epitélio cilíndrico simples, algumas células não atingem a superfície, mas todas se apoiam sobre a membrana basal, que foi PAS- (Figura 8B).
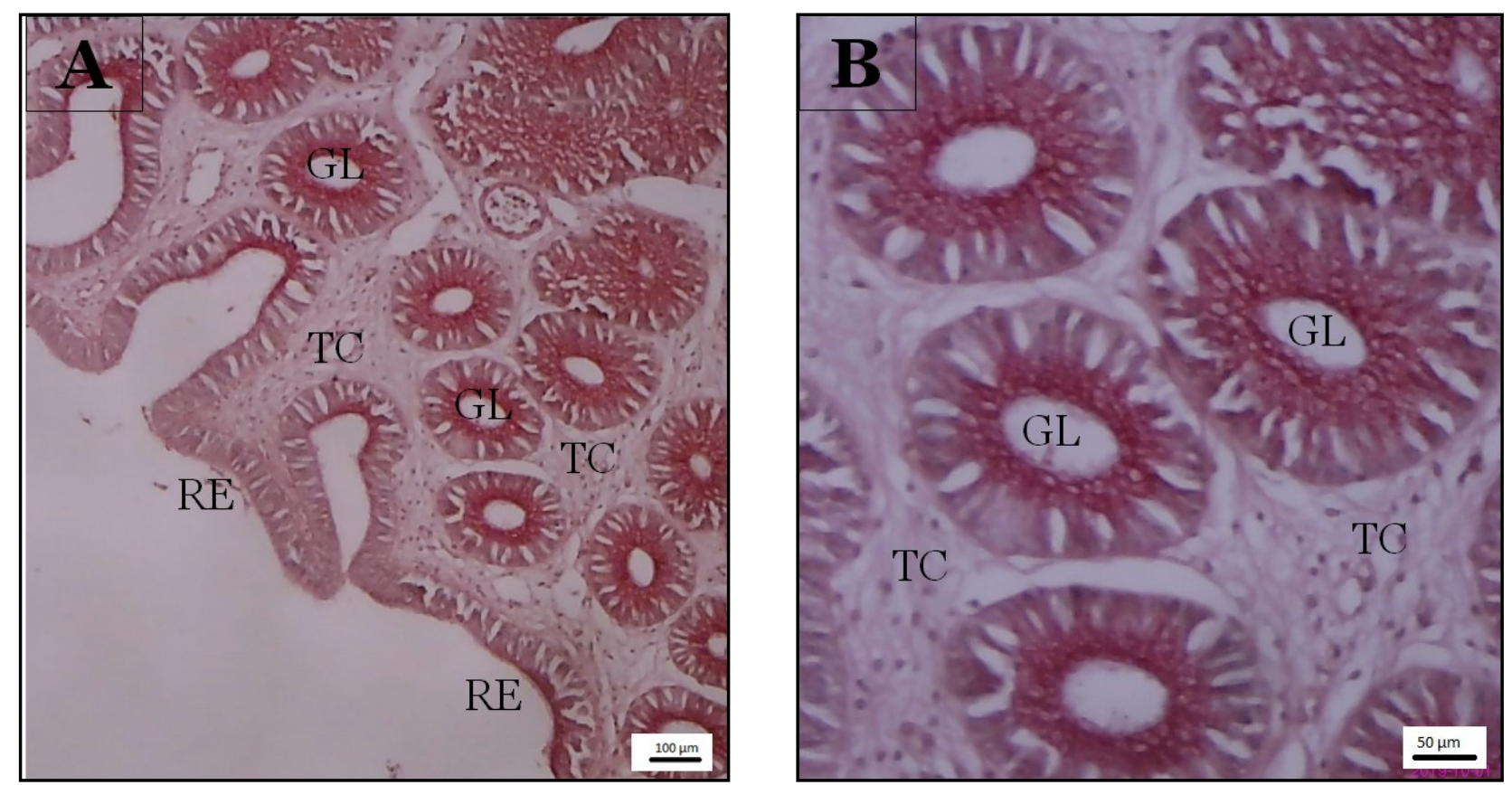

Figura 8. Histoquímica efetuada na Zona $C l u b$ da glândula oviducal de uma fêmea adulta 5 de $P$. glauca. PAS+ foi a região glandular (GL). Figura A. Papilas e túbulos glandulares revestidos com epitélio ciliado. Figura B. Túbulos glandulares revestidos com epitélio ciliado no lúmen. Tecido conjuntivo fracamente vascularizado (TC), região epitelial (RE) e a membrana basal foram PAS-. 


\section{Zona Papillary}

Nesta zona o corante PAS atuou de maneira semelhante à zona $C l u b$, ou seja, a reação foi PAS+ apenas na região glandular e PAS- na região epitelial, no tecido conjuntivo fracamen-

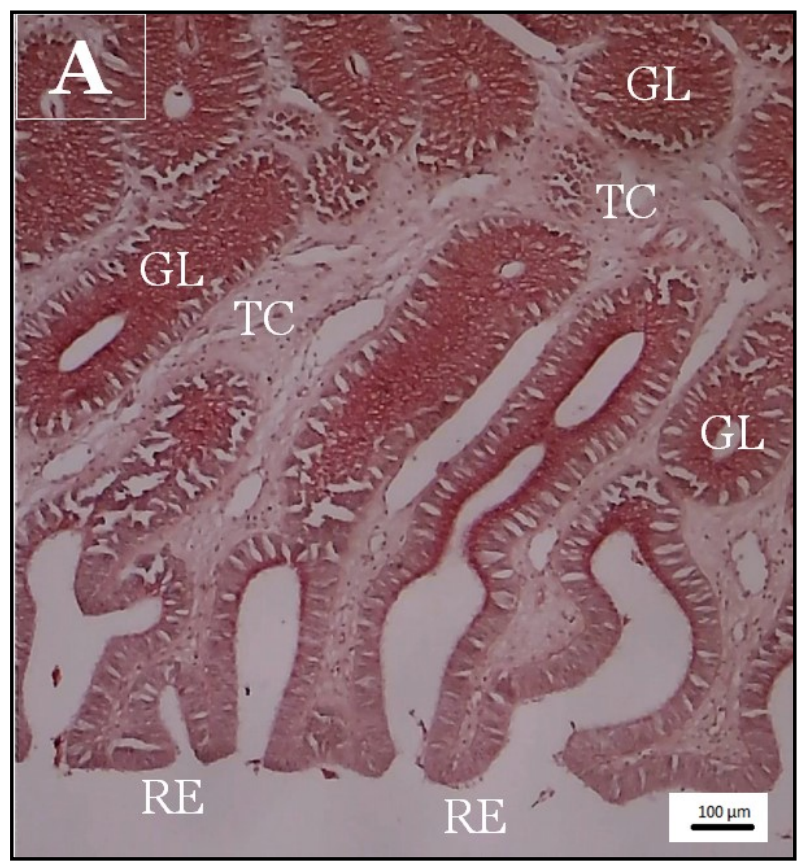

te vascularizado e na membrana basal (Figuras 9A e 9B). As células do tecido cilíndrico simples ciliado coraram positivamente ao redor dos túbulos glandulares (Figura 9B). Também nessas células a atividade secretora é intensa pela presença de grânulos e vesículas.

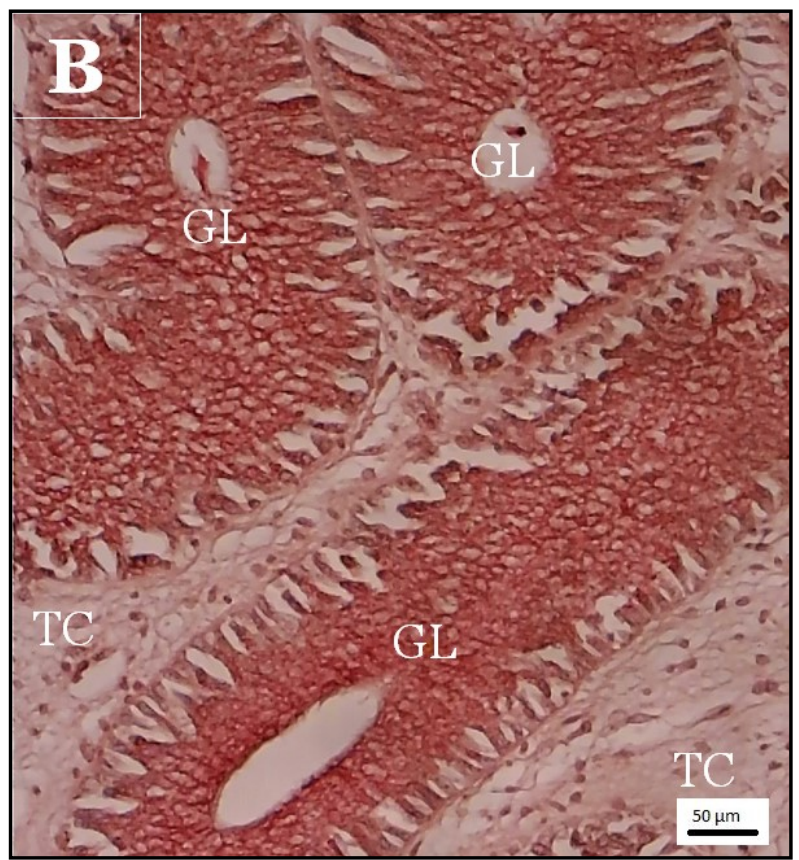

Figura 9. Histoquímica efetuada na Zona Papillary da glândula oviducal de uma fêmea adulta 5 de $P$. glauca. PAS+ foi a região glandular (GL). Figura A. Papilas e túbulos glandulares revestidos com epitélio ciliado. Figura B. Túbulos glandulares revestidos com epitélio ciliado no lúmen. Tecido conjuntivo fracamente vascularizado (TC), região epitelial (RE) e membrana basal foram PAS-.

\section{Zona Baffle}

Nesta zona, a reação foi totalmente PAS-, ou seja, tanto na região epitelial como na glandular (Figuras 10A e 10B). No tecido conjuntivo fracamente vascularizado, bem como na membrana basal a reação também foi PAS(Figuras 10A e 10B). Nesta zona portanto, não se observou atividade secretora de glicosaminoglicanos neutros (Figura 10B).

\section{Zona Terminal}

Da mesma forma que na zona Baffle, a reação foi PAS- na zona Terminal (Figuras 11A e 11B). Mesmo os feixes de espermatozoides nos túbulos glandulares apresentaram a reação PAS- (Figuras 11B). Também no tecido conjuntivo fracamente vascularizado e na membrana basal a reação foi PAS- (Figura 11B). Portanto não há sinais de secreção de glicosaminoglicanos neutros nessa zona.

\section{Azul alciano (AB)}

\section{Zona Club}

Nesta zona a coloração foi $\mathrm{AB}+$ nas regiões epitelial e glandular (Figura 12A e B). Apenas a zona apical das células do tecido cilíndrico simples ciliado foi $\mathrm{AB}+$ (Figura 12B). A reação $\mathrm{AB}+$ foi indicativa de atividade secretora de Glicosaminoglicanos Ácidos (sulfatados e não sulfatados).

\section{Zona Papillary}

Fenômeno semelhante foi observado nesta zona, já que a coloração foi $\mathrm{AB}+$ na região glandular e gradativamente $\mathrm{AB}+$ na região epi- 

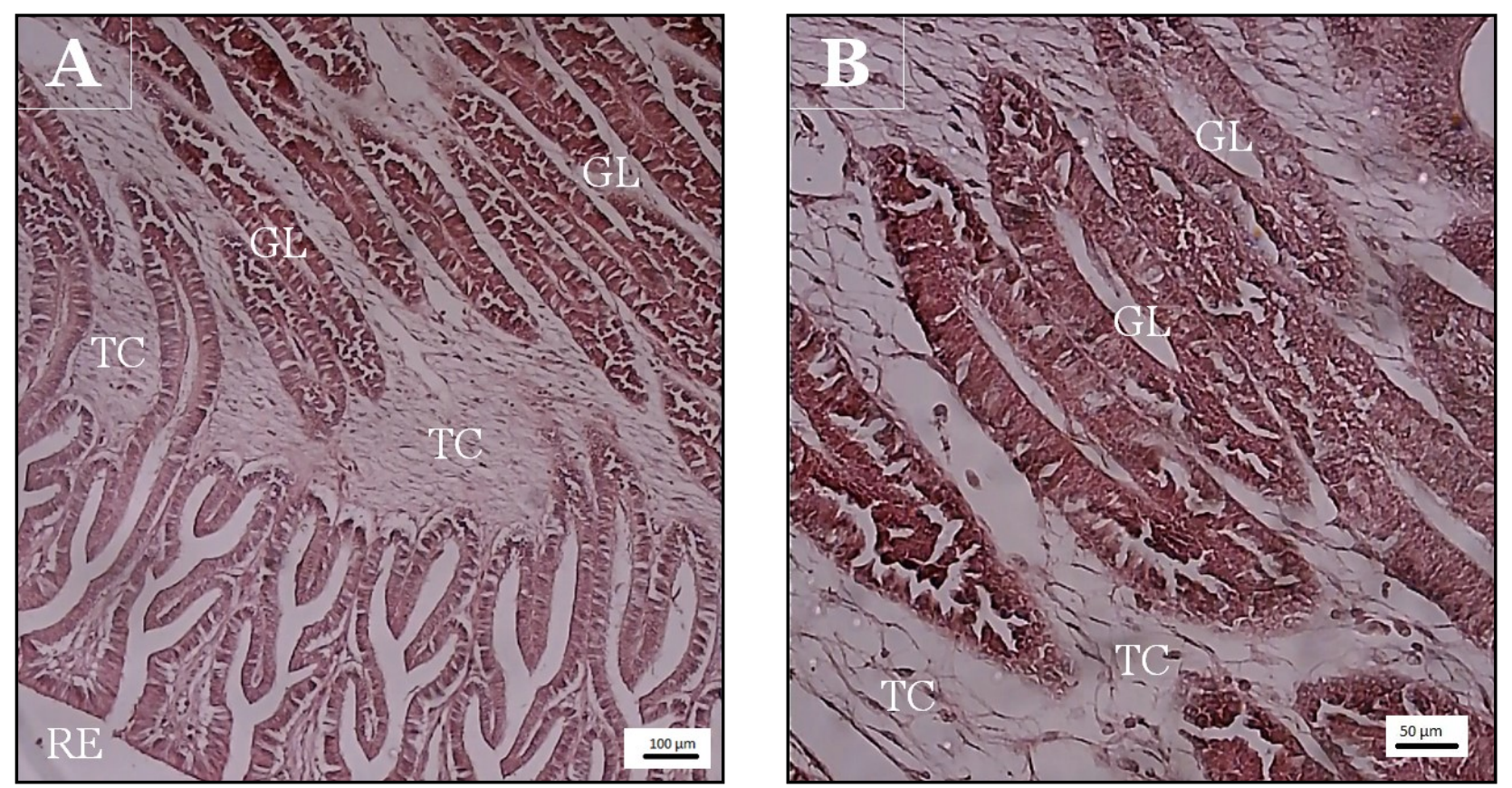

Figura 10. Histoquímica efetuada na Zona Baffle da glândula oviducal de uma fêmea adulta 5 de $P$. glauca. Figura A - Papilas e túbulos glandulares revestidos de epitélio cilíndrico ciliado. Figura B - Túbulos glandulares revestidos de epitélio ciliado no lúmen. Regiões PAS- foram a região epitelial (RE), a região glandular (GL), tecido conjuntivo fracamente vascularizado (TC) e membrana basal. Não houve reação PAS+.
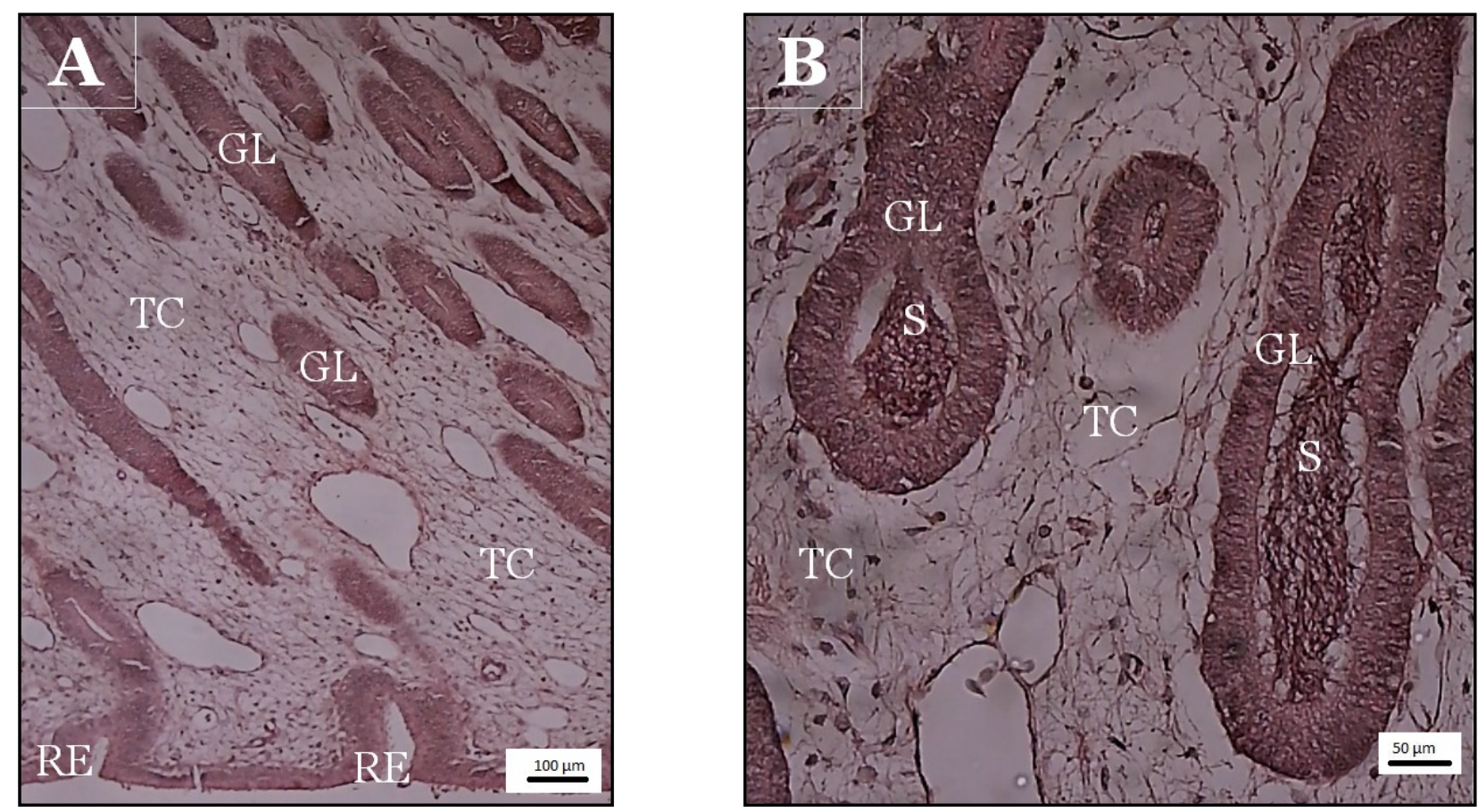

Figura 11. Histoquímica efetuada na Zona Terminal da glândula oviducal de uma fêmea adulta 5 de $P$. glauca. Figura A. Região epitelial e túbulos glandulares cobertos com epitélio cilíndrico ciliado. Figura B. Túbulos glandulares revestidos com epitélio cilíndrico ciliado e armazenando "tufos" de espermatozoides. Regiões PAS- foram a região epitelial (RE), a região glandular (GL), o tecido conjuntivo fracamente vascularizado (TC), a membrana basal e os espermatozoides (S). Não houve reação PAS+. 

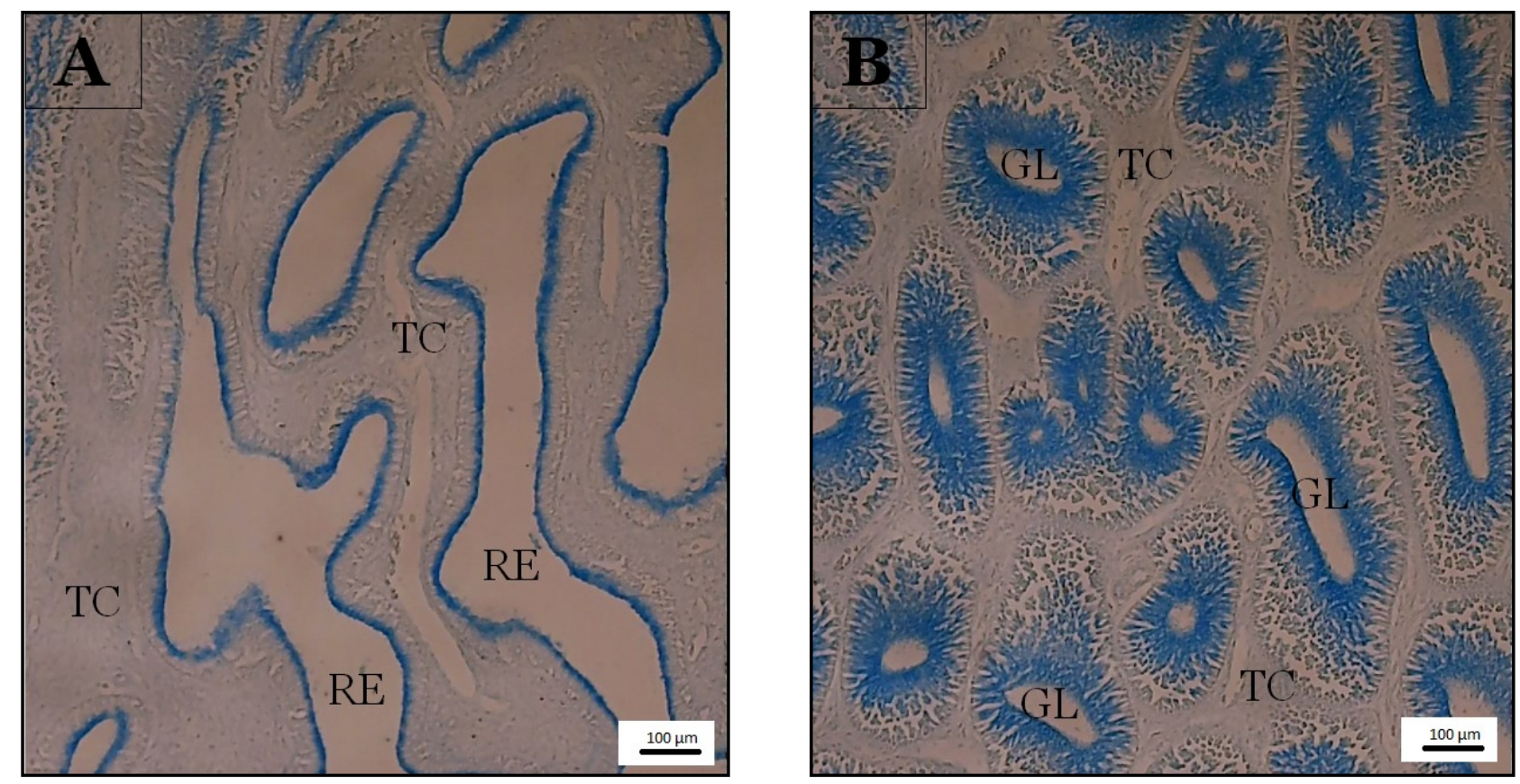

Figura 12. Histoquímica efetuada na Zona $C l u b$ da glândula oviducal de uma fêmea adulta 5 de $P$. glauca. Figura A. Papilas cobertas com epitélio cilíndrico ciliado. Figura B. Túbulos glandulares com epitélio cilíndrico ciliado no lúmen. Reação $\mathrm{AB}+$ foi na região epitelial (RE) e zona glandular (GL). Tecido conjuntivo fracamente vascularizado (TC) e membrana basal foram $\mathrm{AB}-$.

telial, no sentido externo e interno das papilas (Figura 13A). Neste último caso, este fenômeno parece estar associado a um artefato de descolamento do tecido glandular, devido ao proces- samento. Nos túbulos glandulares, apenas a zona apical das células do tecido cilíndrico simples ciliado foi $\mathrm{AB}+$ (Figura 13B). O tecido conjuntivo fracamente vascularizado e a membra-
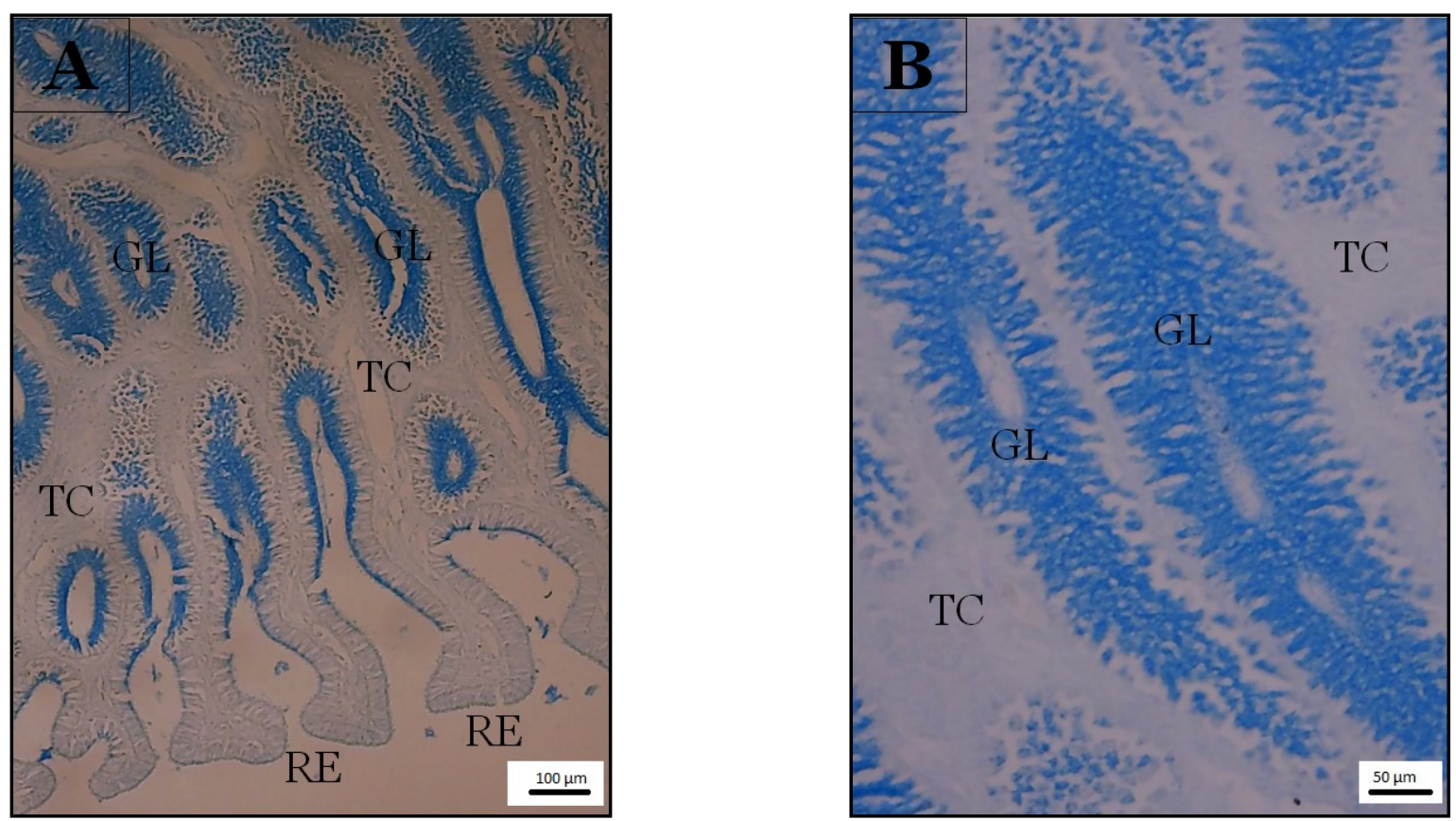

Figura 13. Histoquímica efetuada na Zona Papillary da glândula oviducal de uma fêmea adulta 5 de $P$. glauca. Figura A. Papilas e túbulos glandulares cobertos com epitélio cilíndrico ciliado. Figura B. Túbulos glandulares revestidos com epitélio cilíndrico ciliado no lúmen. Reação $\mathrm{AB}+$ ocorreu na zona glandular (GL). Na região epitelial (RE) houve gradação na intensidade da coloração e, portanto, foi gradualmente $\mathrm{AB}+$ no sentido externo-interno das papilas. Tecido conjuntivo fracamente vascularizado (TC) e membrana basal foram AB-. 
na basal foram $\mathrm{AB}$ - (Figuras 13A e 13B) .

\section{Zona Baffle}

Neste caso a reação foi $\mathrm{AB}$ - desde a regi-

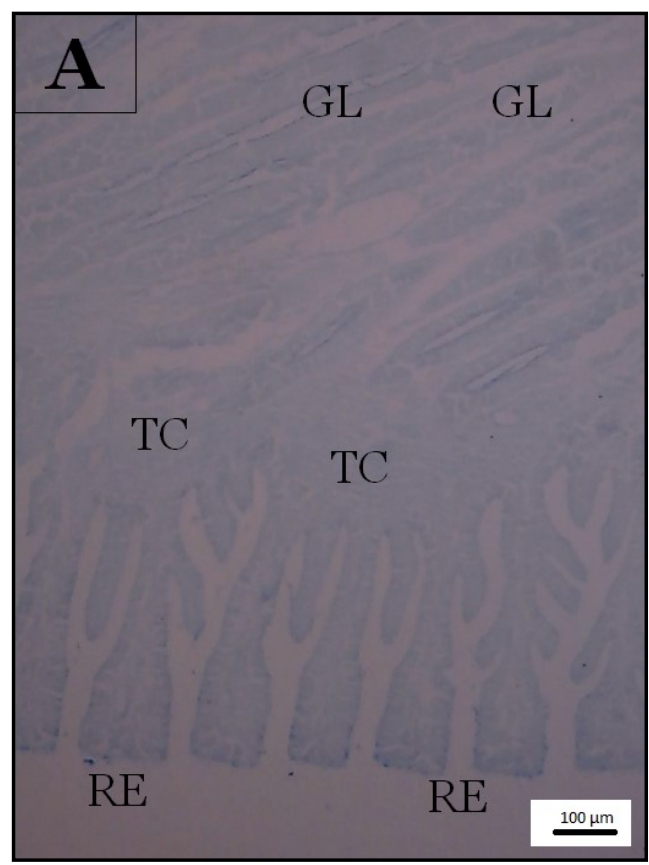

ão epitelial (lúmen da GO), tecido conjuntivo fracamente vascularizado e membrana basal (Figuras 14A e 14B). A reação também foi ABna região glandular (Figura 14 B).

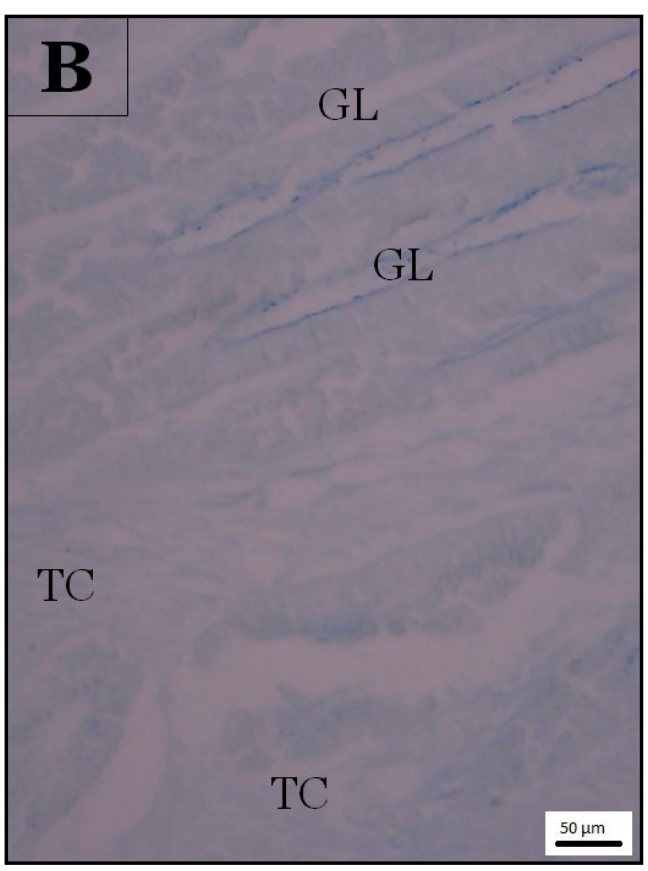

Figura 14. Histoquímica efetuada na Zona Baffle da glândula oviducal de uma fêmea adulta 5 de $P$. glauca. Figura A - Papilas e túbulos glandulares. Figura B - Túbulos glandulares. Reação foi AB- na região epitelial (RE), no tecido conjuntivo fracamente vascularizado (TC) e na membrana basal. Foi também AB- na região glandular (GL).

\section{Zona Terminal}

Não houve reação $\mathrm{AB}+$ nas zonas epitelial e glandular, onde há o tecido colunar simples e ciliado (Figura 15A). As secreções dentro dos túbulos, "banhando" os espermatozoides também não sofreram reação $\mathrm{AB}+$ (Figura 15B).

Uma síntese dos experimentos de histoquímica é apresentada na tabela 3.

Como os melhores cortes obtidos para a análise histológica e histoquímica foram apenas de fêmeas adultas em estágio 5 , não foi possível avaliar e demonstrar, se existentes, as diferenças na estrutura histológica e secretora da GO entre estados de maturação.

\section{Discussão}

Estudos histológicos sobre a GO em tubarões-azuis já foram previamente realizados por alguns autores (Stevens, 1974, Pratt, 1979, 1993, Rangel et al., 2015). Entretanto, este é o primeiro envolvendo a histoquímica na GO desta espécie. Apesar do pequeno número de amostras obtidas (5), como o objetivo deste trabalho foi de apenas caracterizar a estrutura e função da GO desta espécie e não de conhecer todo o ciclo reprodutivo e as possíveis variações histológicas/histoquímicas entre as fêmeas do mesmo ou de diferentes estados de maturidade sexual, este tamanho amostral foi suficiente.

A comparação da histoquímica da GO entre os diferentes modos reprodutivos observados (Tabela 4), evidenciou para a zona Club das espécies vivíparas analisadas, reação PAS+ nas regiões epiteliais e glandulares, embora esta tenha sido apenas $\mathrm{AB}+$ na região glandular 

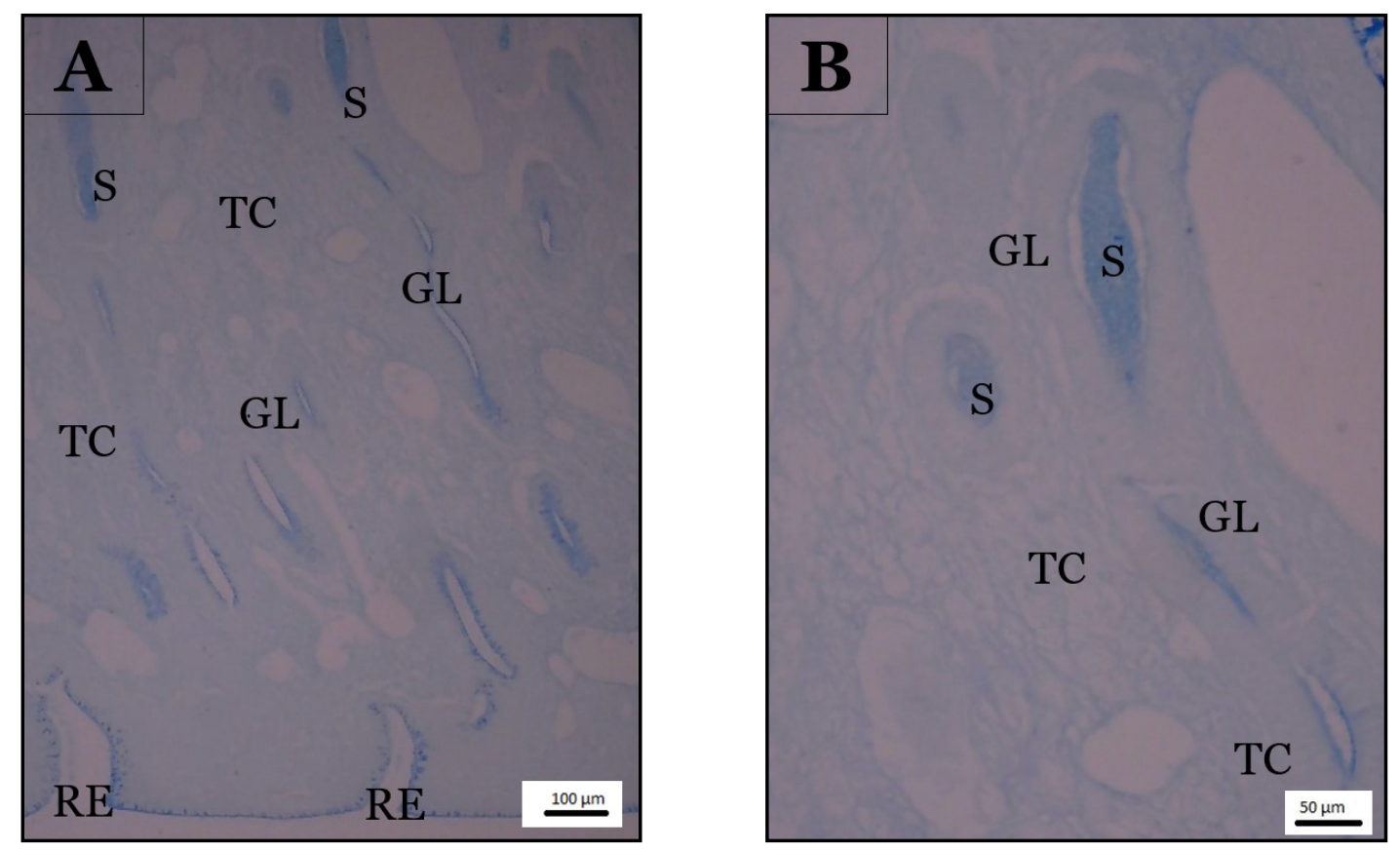

Figura 15. Histoquímica efetuada na Zona Terminal da glândula oviducal de uma fêmea adulta 5 de P. glauca. Figura A. Região epitelial e túbulos glandulares. Figura B. Túbulos glandulares com armazenamento de "tufos" de espermatozoides no lúmen. Reação não foi $\mathrm{AB}+$ na região epitelial (RE) e na região glandular (GL). Os espermatozoides (S), bem como as secreções dentro dos cistos que os armazenam também não apresentaram reação $\mathrm{AB}+$.

de $P$. glauca e AB- em ambas as regiões de $M$. antarcticus. Na zona Club de $P$. glauca há, portanto, a produção de açúcares neutros, ácidos (sulfatados e não sulfatados) e sialoglycoproteínas e em $M$. antarcticus apenas açúcares neutros. Essa diferença entre ambas espécies vivíparas quanto à reação ao $\mathrm{AB}$ possivelmente esteja relacionada com a diferença na viviparidade entre as espécies (placentada - P. glauca; aplacentada - $M$. antarcticus). Nas espécies ovíparas, como é o caso de $C$. milii, $S$. canicula e $S$. bonapartii as células secretoras na zona $C l u b$ produzem uma mistura de material secretor AB+ e PAS+. (Rusaouën, 1976, Smith et al., 2004, Galindez et al., 2010).

Na zona Papillary de $P$. glauca a reação foi $\mathrm{PAS}+\mathrm{e} \mathrm{AB}+$ apenas na região glandular. $\mathrm{Em}$ $M$. antarcticus, outra espécie vivípara, porém aplacentada, a reação foi PAS+ e AB- em ambas regiões (Storrie et al., 2008) (Tabela 4). Essas diferenças na reação ao PAS e AB possivelmente se expliquem pelas distintas modalidades de viviparidade. Por sua vez nas espécies ovíparas houve positividade ao $\mathrm{AB}$ nas duas regiões para S. bonapartii, C. milii e $S$. canicula (Knight et al., 1996, Smith et al., 2004, Galindez et al., 2010). Entretanto a reação foi PAS+ apenas em S. bonapartii (Tabela 4). Portanto, ocorrem diferenças interespecíficas nas reações ao corante PAS dentro do grupo dos condrícteos ovíparos.

A morfologia das zonas Club e Papillary em P. glauca foram semelhantes à de $M$. antarcticus, espécie vivípara não placentária, com diferenças no formato e número de túbulos glandulares (Storrie et al., 2008). Geralmente a zona Club é conhecida como "Zona de produção de Albumina" e a zona Papillary como "Zona de produção de Muco" (Hamlett et al., 1998a, Hamlett \& Koob, 1999). De acordo com Pratt (1979) a zona Papillary no tubarão-azul é ausente quando imaturo, ou reduzida em maturação. Rangel et al. (2015) observou que a largura dessa zona varia de acordo com o ciclo reprodutivo, sendo visualizada em fêmeas nos estágios iniciais de gravidez, como foi o caso do presente estudo. $\mathrm{O}$ material secretado nas duas zonas basicamente é composto de mucopolissacarídeos neutros, havendo, entretanto, uma variação na composição química em função do 
Tabela 3. Resultados dos testes de histoquímica aplicados à glândula oviducal de fêmeas maturas de P. glauca. PAS - Ácido Periódico-Schiff; AB - Azul alciano.

\begin{tabular}{ccc}
\hline Glândula oviducal & \multicolumn{2}{c}{ Reação ao corante } \\
(Zonas) & PAS & AB \\
\hline (1) Zona Club & & \\
(a) Região epitelial & - & - \\
Epitélio cilíndrico simples ciliado & - & - \\
Tecido conjuntivo fracamente vascularizado & & - \\
(b) Região glandular & - & - \\
Tecido conjuntivo fracamente vascularizado & + & - \\
Epitélio cilíndrico simples ciliado & - & - \\
Membrana basal & & \\
\hline (2) Zona Papillary \\
(a) Região epitelial & - & - \\
Epitélio cilíndrico simples ciliado & - & + \\
Tecido conjuntivo fracamente vascularizado & & - \\
(b) Região glandular & - & \\
\hline Tecido conjuntivo fracamente vascularizado & - & \\
Epitélio cilíndrico simples ciliado & & \\
Membrana basal & & - \\
\hline
\end{tabular}

(3) Zona Baffle

(a) Região epitelial

Epitélio cilíndrico simples ciliado

Tecido conjuntivo fracamente vascularizado

\section{(b) Região glandular}

Tecido conjuntivo fracamente vascularizado

Epitélio cilíndrico simples ciliado

Membrana basal

\section{(4) Zona Terminal}

(a) Região epitelial

Epitélio cilíndrico simples ciliado

Tecido conjuntivo fracamente vascularizado

(b) Região glandular

Tecido conjuntivo fracamente vascularizado

Epitélio cilíndrico simples ciliado

Membrana basal

Espermatozoides 
modo reprodutivo da espécie, ou seja, em $M$. antarcticus (vivípara aplacentada) não houve reação $\mathrm{AB}+$ tanto na zona Club como Papillary, diferente de $P$. glauca (vivípara placentada) que apresentou reação $\mathrm{AB}+$ nas regiões glandulares, porém PAS- na região epitelial da zona Papillary (Hamlett et al., 2005, Moura et al.,
2011). Na raia $U$. jamaicensis, espécie matrotrófica com leite uterino, segundo La Marca (1961) a zona anterior da GO apresenta túbulos secretores PAS+. Neste caso, os túbulos não secretam gelatina, não havendo, portanto, zonas Club ou Papillary (Hamlett et al., 2005) (Tabela 4).

Tabela 4. Comparação da histoquímica aplicada nas GOs de elasmobrânquios com diferentes modos reprodutivos.

\begin{tabular}{|c|c|c|c|c|c|c|c|c|c|c|c|c|}
\hline Espécie & \multicolumn{2}{|c|}{ P.glauca } & \multicolumn{2}{|c|}{ M. antarcticus } & \multicolumn{2}{|c|}{ S. bonapartii } & \multicolumn{2}{|c|}{ C. milii } & \multicolumn{2}{|c|}{ S. canicula } & \multicolumn{2}{|c|}{ U.jamaicencis } \\
\hline Fonte & \multicolumn{2}{|c|}{$\begin{array}{l}\text { Presente } \\
\text { estudo }\end{array}$} & \multicolumn{2}{|c|}{$\begin{array}{l}\text { Storrie } \text { et al. } \\
\quad(2008)\end{array}$} & \multicolumn{2}{|c|}{$\begin{array}{l}\text { Galindez et } \\
\text { al., } 2010\end{array}$} & \multicolumn{2}{|c|}{$\begin{array}{l}\text { Smith et } \\
\text { al., } 2004\end{array}$} & \multicolumn{2}{|c|}{$\begin{array}{l}\text { Knight et } \\
\text { al., } 1996\end{array}$} & \multicolumn{2}{|c|}{$\begin{array}{l}\text { Hamlett et } \\
\text { al., 1998a }\end{array}$} \\
\hline Modo reprodutivo & \multicolumn{2}{|c|}{$\begin{array}{l}\text { Viviparidade } \\
\text { placentária }\end{array}$} & \multicolumn{2}{|c|}{$\begin{array}{l}\text { Viviparidade } \\
\text { aplacentária }\end{array}$} & \multicolumn{2}{|c|}{ Oviparidade } & \multicolumn{2}{|c|}{ Oviparidade } & \multicolumn{2}{|c|}{ Oviparidade } & \multicolumn{2}{|c|}{$\begin{array}{l}\text { Matrotrofia c/ } \\
\text { leite uterino }\end{array}$} \\
\hline Reação ao corante & PAS & $\mathrm{AB}$ & PAS & $\mathrm{AB}$ & PAS & $\mathrm{AB}$ & PAS & $\mathrm{AB}$ & PAS & $\mathrm{AB}$ & & PAS \\
\hline (1) Zona Club & & & & & & & & & & & $\begin{array}{l}\text { (1) Zona } \\
\text { anterior }{ }^{1}\end{array}$ & + \\
\hline (a) Região epitelial & & & & & & & & & & & $\begin{array}{l}\text { (2) Zona } \\
\text { posterior }\end{array}$ & - \\
\hline $\begin{array}{l}\text { Epitélio cilíndrico sim- } \\
\text { ples ciliado }\end{array}$ & - & + & + & - & + & + & + & + & + & + & & \\
\hline \multicolumn{13}{|l|}{ (b) Região glandular } \\
\hline $\begin{array}{l}\text { Epitélio cilíndrico } \\
\text { simples ciliado }\end{array}$ & + & + & + & - & + & + & + & + & + & + & & \\
\hline
\end{tabular}

\section{(2) Zona Papillary}

(a) Região epitelial

Epitélio cilíndrico simples ciliado

\section{(b) Região glandular}

Epitélio cilíndrico simples ciliado

\section{(3) Zona Baffle}

\section{(a) Região epitelial}

Epitélio cilíndrico simples ciliado

\section{(b) Região glandular}

Epitélio cilíndrico simples ciliado

\section{(4) Zona Terminal}

\section{(a) Região epitelial}

Epitélio cilíndrico simples ciliado

\section{(b) Região glandular}

Epitélio cilíndrico simples ciliado

Espermatozoides

\footnotetext{
1 Não ocorre zonas Club, Papillary e Terminal. Zona Baffle sem papilas.
} 
Na zona Baffle das espécies ovíparas, não foi detectada a presença de reação positiva aos corantes. No tubarão-azul, o fenômeno foi semelhante (Tabela 4). Entretanto, em P. glauca por ser uma espécie vivípara placentada, não há a necessidade da secreção de uma verdadeira "casca", mas apenas de um envoltório membranoso e quase transparente, ao contrário das espécies ovíparas (Hamlett \& Koob, 1999). Já o material da casca do ovo da quimera $C$. milii é semelhante a um polímero de cristal líquido. Em $S$. canicula, espécie ovípara, a casca do ovo é composta de fibrilas de colágeno (Knight et al., 1996). Em $S$. bonapartii, espécie ovípara costeira, a zona Baffle também foi PAS- e ABtanto na região epitelial como glandular, haja vista a ausência da secreção de carboidratos (Galindez et al., 2010). Na zona Baffle de $C$. milii, a superfície das lamelas é composta de epitélio colunar simples ciliado, da mesma forma que em $P$. glauca. Por sua vez, na raia $U$. jamaicensis, a zona Baffle não apresenta papilas, perdendo-se a capacidade de produzir algum tipo de cápsula (Hamlett et al., 1996, 1998a, 1999a, 1999b, Spieler et al., 2013).

Finalmente para a zona Terminal do tubarão-azul não houve reação $\mathrm{AB}+$ nas duas regiões e nos espermatozoides. Por sua vez, nas espécies ovíparas houve reações $\mathrm{PAS}+\mathrm{e} \mathrm{AB}+$, nas regiões glandulares (Tabela 4). Knight et al. (1996) e Gilbert et al. (1968) consideram que este fenômeno nas ovíparas possa se explicar pela capacidade que os túbulos glandulares teriam de secretar substâncias nutritivas aos espermatozoides e que reagem positivamente a esses corantes. No caso das regiões epiteliais, dependendo da espécie, a reação foi PAS(Tabela 4). Em C. milii a reação foi também $\mathrm{AB}+$ nos espermatozoides (Smith et al., 2004). Nessa espécie ovípara, apenas glândulas tubulares estão dispersas na zona Terminal, onde desempenham duas funções: (1) armazenar esperma e (2) produção de finos pelos que recobrem o lado externo da cápsula do ovo (Smith et al., 2004). Esses túbulos são compostos de células colunares curtas ciliadas à semelhança do que ocorre em P. glauca. Concentrações de esperma são encontradas nas regiões mais profundas desses túbulos em $C$. milii, ca- racterizados por células secretoras $(\mathrm{AB}+)$ (Smith et al., 2004). Na raia ovípara, S. bonapartii, a zona Terminal serve como depósito de esperma nos túbulos da região glandular. Neste caso a histoquímica foi $\mathrm{PAS}+\mathrm{e} \mathrm{AB}+$ tanto na região epitelial como glandular, havendo, portanto, a secreção de glicosaminoglicanos neutros e ácidos (Galindez et al., 2010). Em $P$. glauca essa zona está apenas relacionada com o armazenamento de esperma e com alguma secreção final da membrana que envolve o embrião.

No presente estudo uma fêmea adulta grávida em estágio 5 (Colonello et al., 2011) foi observada em dezembro de 2004 inseminada, ou seja, com esperma na zona Terminal da GO, como massas de filamentos coradas de roxo, localizadas na região glandular. A presença de espermatozoides na GO dessa espécie é frequente, e também foi detectada por Pratt (1979) em 49\% das fêmeas analisadas em um período de três anos. Por sua vez, Hazin (1991) encontrou esperma em $86 \%$ das fêmeas observadas (20 na fase pré-ovulatória, três na pósovulatória, duas subadultas e 13 grávidas). Storrie et al. (2008) encontraram ao longo do ano esperma armazenado nas GOs de fêmeas de $M$. antarcticus imaturas, maturas nãográvidas, grávidas e pós-parto. Moderadas quantidades de esperma foram observadas em fêmeas adultas grávidas, em fase pós-ovulatória por Rangel et al. (2015). A sazonalidade do ciclo reprodutivo irá estabelecer o momento em que o esperma será armazenado (Rangel et al., 2015). No caso desta espécie, a primaveraverão seria a época na costa sul do Brasil (Amorim, 1992).

A ocorrência de glândula oviducal em diferentes espécies de tubarões pelágicos, como é o caso do tubarão-azul, $P$. glauca, seria uma adaptação evolutiva a um estilo de vida migratório, e densidades populacionais baixas (Pratt, 1993). Neste caso, o tempo de residência do esperma nas glândulas oviducais seria da ordem de semanas a meses, com o esperma fracamente "empacotado" nos túbulos secretores, com as cabeças posicionadas no sentido "contracorrente", bem como afastados da saída para o lúmen central. Os espermatozoides nos 
tubarões, dependendo da espécie, podem ficar armazenados nas glândulas oviducais em um período de dias, meses a alguns anos, antes de fecundarem os ovócitos. No tubarão-azul o tempo de armazenamento de esperma é relativamente curto, se comparado a $S$. retifer, cujo período de armazenamento pode ultrapassar os dois anos. Já em $M$. antarcticus seria de 13 meses (Castro et al., 1988, Storrie et al., 2008).

Com as informações obtidas na Tabela 4 não foi possível estabelecer um padrão histoquímico que diferenciasse as espécies vivíparas das ovíparas. Ao que tudo indica, existem reações positivas ou negativas aos corantes, dependendo do modo reprodutivo, da espécie, zona e região dentro da glândula.

Ao comparar a histoquímica da GO de P. glauca com outras espécies vivíparas (Tabela 5), de início se observa que nas zonas $C l u b$ e Papillary as secreções produzidas nos túbulos glandulares apresentam positividade ao PAS, ou seja, são muccinas neutras. Isso já havia sido observado por Hamlett et al. (2002a) em outra espécie vivípara placentada, como é o

Tabela 5. Comparação da histoquímica aplicada nas GOs de elasmobrânquios vivíparos. As cores amarelas representam semelhanças no PAS e as azuis semelhanças no AB.

\begin{tabular}{|c|c|c|c|c|c|}
\hline Espécie & $\begin{array}{c}\text { Prionace } \\
\text { glauca }\end{array}$ & $\begin{array}{c}\text { Mustelus } \\
\text { antarcticus }\end{array}$ & $\begin{array}{c}\text { Iago } \\
\text { omanensis }\end{array}$ & $\begin{array}{l}\text { Mustelus } \\
\text { schmitti }\end{array}$ & $\begin{array}{c}\text { Etmopterus } \\
\text { spinax }\end{array}$ \\
\hline Fonte & $\begin{array}{c}\text { Presente } \\
\text { estudo }\end{array}$ & $\begin{array}{l}\text { Storrie et al. } \\
(2008)\end{array}$ & $\begin{array}{l}\text { Hamlett et al. } \\
(2002 b)\end{array}$ & $\begin{array}{c}\text { Elías } \\
(2015) \\
\end{array}$ & $\begin{array}{l}\text { Porcu et al. } \\
\quad(2015)\end{array}$ \\
\hline Modo reprodutivo & $\begin{array}{l}\text { Viviparidade } \\
\text { placentária }\end{array}$ & $\begin{array}{l}\text { Viviparidade } \\
\text { aplacentária }\end{array}$ & $\begin{array}{l}\text { Viviparidade } \\
\text { placentária }\end{array}$ & $\begin{array}{l}\text { Viviparidade } \\
\text { aplacentária }\end{array}$ & $\begin{array}{l}\text { Viviparidade } \\
\text { aplacentária }\end{array}$ \\
\hline Reação ao corante & $\begin{array}{ll}\text { PAS } & \mathrm{AB}\end{array}$ & $\begin{array}{ll}\text { PAS } & \mathrm{AB}\end{array}$ & PAS $\quad \mathrm{AB}$ & $\begin{array}{ll}\text { PAS } & A B \\
\end{array}$ & PAS $\quad \mathrm{AB}$ \\
\hline
\end{tabular}

(1) Zona "Club"

(a) Região epitelial

Epitélio cilíndrico simples ciliado

(b) Região glandular

Epitélio cilíndrico simples ciliado

(2) Zona "Papilar"

(a) Região epitelial

Epitélio cilíndrico simples ciliado

(b) Região glandular Epitélio cilíndrico simples ciliado

\section{(3) Zona "Baffle"}

\section{(a) Região epitelial}

Epitélio cilíndrico simples ciliado

(b) Região glandular

Epitélio cilíndrico simples ciliado

\section{(4) Zona "Terminal"}

\section{(a) Região epitelial}

Epitélio cilíndrico simples ciliado

(b) Região glandular

Epitélio cilíndrico simples ciliado

Espermatozoides

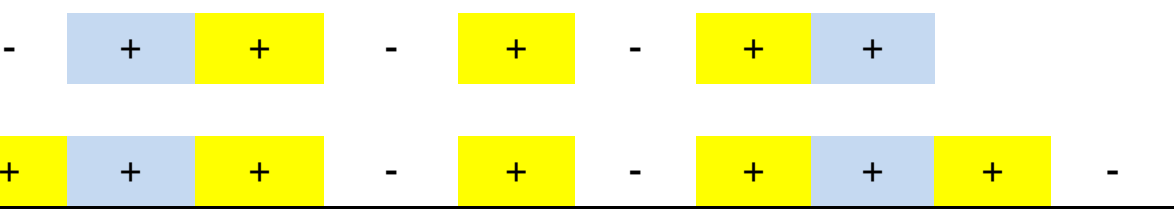

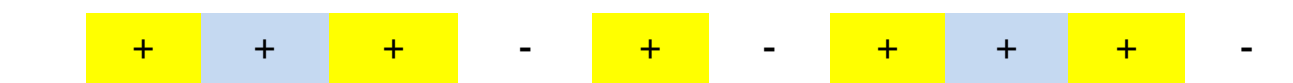

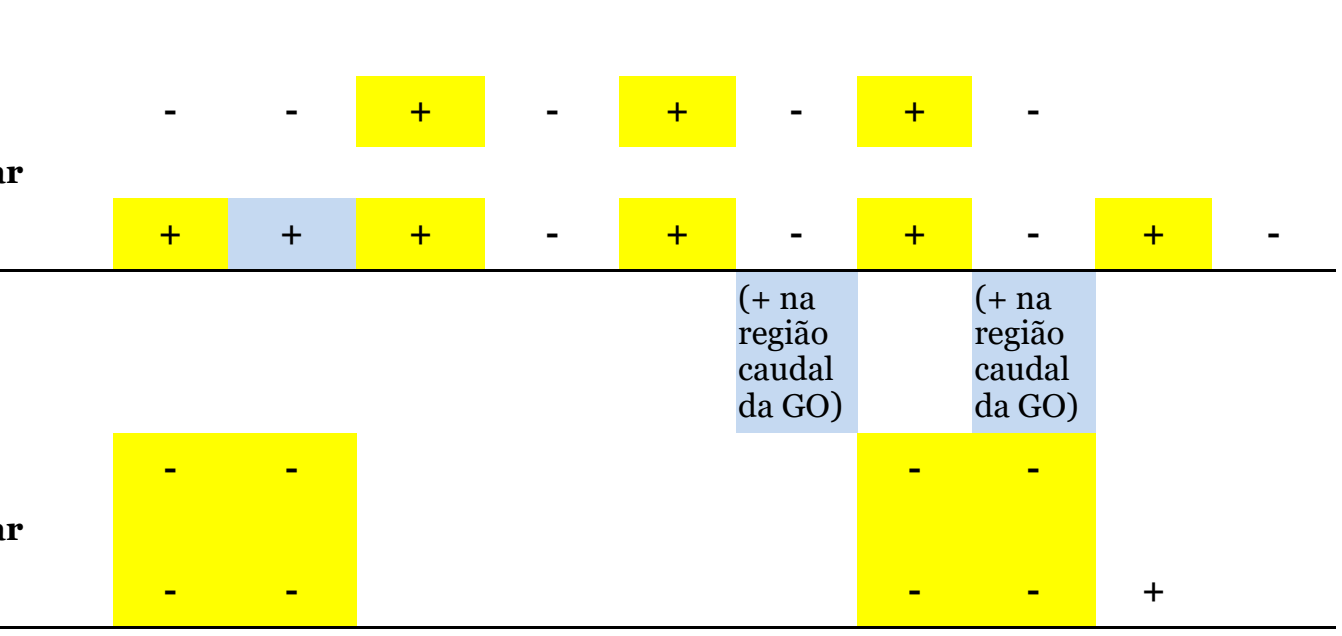


caso de Iago omanensis. Por outro lado, $P$. glauca (vivíparo placentado) e Mustelus schmitti (vivíparo aplacentado) apresentaram em comum também positividade ao $\mathrm{AB}$ na zona $C l u b$, o que indicou também secreções de muccinas ácidas nos seus túbulos glandulares. $\mathrm{Na}$ zona Papillary houve apenas positividade ao AB nos túbulos glandulares de $P$. glauca e nas regiões mais caudais dessa zona em $I$. omanensis e M. schmitti (Tabela 5). Percebe-se, pois, que mesmo entre as espécies vivíparas ocorrem pequenas diferenças nas composições químicas das secreções, possivelmente como resultado das variações interespecíficas da viviparidade (Elías 2015), bem como pelo fato de algumas serem placentadas ( $P$. glauca, Iago omanensis) e outras não (Mustelus antarcticus, $M$. schmitti e Etmopterus spinax) e possivelmente haver diferenças na constituição química das gelatinas produzidas (Hamlett et al., 2002a). Na zona Baffle em geral, para as espécies vivíparas não foi detectada reação positiva tanto para o PAS, quanto o AB, com exceção de Etmopterus spinax (Porcu et al., 2015), onde foi observado acúmulo de materiais secretores PAS+ e PASna região mais profunda dos túbulos glandulares, próximo ao tecido conectivo. Uma característica comum em espécies vivíparas é a redução da cobertura do ovo a uma membrana flexível, como é o caso dos gêneros Mustelus, Squalus, onde essa membrana apresenta o formato de uma "vela" e rodeando os embriões (SerraPereira et al., 2011). Na zona Terminal os epitélios de $M$. schmitti e $E$. spinax foram $\mathrm{AB}+$, produzindo muccinas sulfatadas ácidas (Tabela 5). Já no caso de $P$. glauca, não houve reação positiva aos corantes PAS e AB nessa região. A positividade ao PAS foi observada na região epitelial de I. omanensis e nos túbulos glandulares dessa zona em I. omanensis e E. spinax. Os espermatozoides coraram $\mathrm{AB}+\mathrm{e} \mathrm{PAS}+\mathrm{em}$ E. spinax, porém não reagiram positivamente a esses corantes em P. glauca.

Foram constatados problemas com a coloração de PAS, uma vez que em zonas espectáveis de haver uma reação positiva (e.g. zona Club e Papillary), não é apresentada a cor magenta característica. Uma possível explicação para esse problema, embora tenham sido feitas novas tentativas para corrigir isso, por meio de novas colorações em diferentes lâminas, seja devido à validade ou qualidade do corante utilizado no procedimento histoquímico. A coloração PAS é muito sensível à qualidade dos reagentes, devendo ter especial atenção com a validade dos reagentes e se necessário ensaiar com reagentes de diferentes fabricantes, pois pode levar a melhores resultados. Nas imagens apresentadas também se observa uma desidratação severa dos tecidos devido ao processamento. Lamentavelmente esses fatores limitaram a qualidade dos resultados histoquímicos com a coloração PAS e futuramente haverá de se considerar cuidadosamente a qualidade do corante bem como na maneira em que é feita a desidratação progressiva em banhos com álcool etílico de concentração crescente (70\%, 90\% e 100\%), para assim não danificar os tecidos.

A arquitetura e o desenvolvimento da glândula estão relacionados com a espécie, o modo reprodutivo, estágio de maturidade, e a época do ano (Hamlett et al., 1998a, Galindez et al., 2010, Serra-Pereira et al., 2011). No caso de $P$. glauca, a GO é semelhante à de outros elasmobrânquios vivíparos, como é o caso de Squalus acanthias, Mustelus antarcticus e M. canis e os cações-anjo do gênero Squatina (Capapé et al., 1990, Conrath, 2000, Hamlett et al., 2002a, Hamlett et al., 2005, Storrie et al., 2008), ou seja, morfologia externa simétrica, com duas protrusões nas superfícies anteriores laterais (Rangel et al., 2015), dando-lhe um formato de "coração". Neste caso, a zona Baffle apresenta menos fendas transversais, se comparado aos ovíparos, pois a cobertura do ovo é reduzida a uma membrana flexível que rodeia os embriões e desaparece antes do parto. Por sua vez, nas raias elétricas vivíparas da família Narcinidae se observa ausência da GO (Prasad, 1945). Em outra espécie vivípara, Urobatis jamaicensis (Hamlett et al., 1998a) a GO não apresenta as quatro zonas tradicionais (Club, Papillary, Baffle e Terminal), mas apenas duas, e os túbulos não secretam gelatina ou material da cápsula ovígera. Adicionalmente para o vivíparo tubarão-baleia Cetorhinus maximus, não há divisões evidentes na GO e secreções de envoltórios sobre os embriões (Mattews, 1950, 
Hamlett et al., 1998a, 2002a, Storrie et al., 2008, Moura et al., 2011).

No caso das espécies ovíparas, como as raias Raja clavata (Serra-Pereira, et al., 2011), $R$. erinacea (Knight et al., 1996), R. eglanteria (Hamlett et al., 1998a), Sympterygia bonapartii (Galindez et al., 2010), o cação-gato Scyliorhinus canicula (Knight et al., 1996) e o holocéfalo Callorhynchus milii (Smith et al., 2004), estas apresentam as maiores GO em Chondrichtyes, com maior número de fendas transversais na zona Baffle, para assim produzir uma cápsula ovígera mais grossa (Nalini, 1940, Knight et al., 1993, Hamlett et al., 1998a, Hamlett et al., 2005). As zonas Club, Papillary, Baffle e Terminal se mantém, porém, a morfologia das capsulas ovígeras diferem. A GO das raias ovíparas quando maturas se assemelham morfologicamente a um "feijão" (Serra-Pereira et al., 2011). Já no caso da quimera C. milii, durante a época da postura das cápsulas ovígeras, a GO aumenta de tamanho e suas margens laterais expandidas se fundem com o útero (Smith et al., 2004). Serra-Pereira et al. (2011) observaram que o tamanho da glândula oviducal em $R$. clavata aumenta com a maturidade, sendo que toda a morfometria (largura, altura e espessura) foi estatisticamente distinta entre os estágios de maturidade. Também se observou variação no tamanho da GO em fêmeas do mesmo tamanho.

Em termos histológicos, o epitélio cilíndrico simples ciliado que recobre as paredes do lúmen da glândula oviducal nos tubarões-azuis, se assemelhou ao encontrado na zona Terminal do cação Mustelus antarcticus (vivíparo aplacentado), em $M$. canis (vivíparo placentado), nas GOs das raias emplasto Sympterygia acuta e $S$. bonapartii, na raia de esporão Raja clava$t a$, na quimera $C$. milii e no tubarão gato $S$. $c a-$ nicula, que por sua vez são espécies ovíparas (Hamlett et al., 1998a, Smith et al., 2004, Storrie et al., 2008, Galindez \& Estecondo, 2008, Galindez et al., 2010, Serra-Pereira et al., 2011). Esse epitélio apresentou uma grande atividade secretora conforme observado em varias técnicas histoquímicas em mamíferos (Ross et al., 1993), elasmobrânquios (Smith et al., 2004, Serra-Pereira et al., 2011) e constata- do no presente estudo pela sua positividade ao PAS nas regiões glandulares das zonas $C l u b$ e Papillary e pela positividade ao $\mathrm{AB}$ na região epitelial da zona Club (secreção de mucopolissacarídeos ácidos) e nas regiões glandulares das zonas Club e Papillary. O PAS é indicativo de muccinas neutras e glicogênio (Bancroft et al., 1996), sendo estes geralmente epiteliais. As células PAS+ são mais granulosas, com núcleos grandes, basais e cheias de vesículas, com funções secretoras e cílios. Rangel et al. (2015) também observaram a presença de células cilíndricas ciliadas e secretoras nas diversas zonas da GO do tubarão azul, tanto nas regiões epiteliais como glandulares, porém sem ter realizado ensaios com histoquímica, mas apenas coloração com HE.

Segundo Amorim (1992) o tubarão-azul no sul do Brasil copula na primavera-verão, ou seja, entre os meses de novembro a março. Isto foi confirmado no presente estudo pela presença de marcas de cópula em duas fêmeas em janeiro de 2008 e em outras duas no mês de dezembro de 2015.

No presente estudo, além do ganho na experiência de conhecer um pouco da histologia e histoquímica da GO de $P$. glauca e poder compará-las com outras espécies de elasmobrânquios e seus modos reprodutivos distintos, conclui-se que há necessidade de mais estudos de histoquímica nas GOs das diferentes espécies de elasmobrânquios, com o objetivo de entender a composição química das secreções produzidas nas diferentes zonas ao longo da filogenia e ontogenia desse grupo de vertebrados. Também é sugerida microscopia eletrônica para estudar a ultraestrutura de cada uma das células em cada uma das regiões na GO do tubarão-azul e de outras espécies de peixes cartilaginosos.

\section{Referências Bibliográficas}

ALMEIDA-SANTOS, S. M. \& SALOMÃO, M. G. 1997. Long-term sperm storage in the female neotropical rattlesnake Crotalus durissus terrificus (Viperidae: Crotalinae). Jpn. J. Herpetol., 17 (2):46-52. Disponível em:

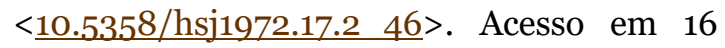


jun. 2019.

AMORIM, A. F. 1992. Estudo da biologia da pesca e reprodução do cação-azul, Prionace glauca L. 1758, capturado no Sudeste e Sul do Brasil. SP. Rio Claro. 205p. (Tese de Doutorado. Instituto de Biociências de Rio Claro, UNESP).

AMORIM, A. F., BRAGA, F. M. S. \& ARFELLI, C. A. 1997. Length-frequency of Prionace glauca L. 1758 caught by Santos longliners off south and southeast of Brazil. Col. Vol. Sci. Pap. ICCAT, 46:430-435.

BANCROFT, J. D., STEVENS, A. \& TURNER, D. R. 1996. Theory and Practice of Histological Techniques. London, Toronto, Churchill Livingstone. $766 \mathrm{p}$.

BIRKHEAD, T. R. \& MØLLER, A. P. 1993. Sexual selection and the temporal separation of reproductive events: sperm storage data from reptiles, birds and mammals. Biol. J. Linn. Soc., 50:295-311.

CASTRO, J. I., BUBUCIS, P. M. \& OVERSTROM, N. A. 1988. The reproductive biology of the chain dogfish, Scyliorhinus retifer. Copeia, 740-746.

CAPAPÉ, C., QUIGNARD, J. P. \& MELLINGER, J. 1990. Reproduction and development of two angel sharks, Squatina squatina and Squatina oculata (Pisces: Squatinidae), off Tunisian coasts: semi-delayed vitellogenesis, lack of egg capsules, and lecithotrophy. J. Fish. Biol., 37:347-356.

COLONELlO, J. H., CHRISTIANSEN, H. E. \& MACCHI, G. J. 2011. Escala de madurez sexual para peces cartilaginosos de la Plataforma Continental Argentina. In: WÖHLER, O. C., CEDROLA P. \& COUSSEAU, M. B. (eds.). Contribuciones sobre biología, pesca y comercialización de tiburones en la Argentina. Aportes para la elaboración del Plan de Acción Nacional. Consejo Federal Pesquero, Buenos Aires: 115-128.

CONRATH, C. L. 2000. Population dynamics of the smooth dogfish, Mustelus canis, in the Northwest Atlantic. Virginia. 93 p. (PhD Dissertation. Virginia Institute of Marine Science).

DEAN, B. 1895. Fishes, Living and Fossil - An outline of their forms and probable relations- hips, Columbia University Biological Series III. New York, MacMillan \& Co. 75p.

DEAN, B. 1906. Chimaeroid Fishes and Their Development. Carnegie I. Wash., :159-172 .

DEAN, B. 1912. Orthogenesis in the egg capsules of Chimaera. B. Am. Mus. Nat. Hist., 31: 3540.

ELÍAS, F. G. 2015. Histochemical study of the oviducal gland and analysis of the sperm storage tubules of Mustelus schmitti Springer, 1939 (Chondrichthyes, Triakidae). Pesq. Vet. Bras., 35(8): 741-748.

GALINDEZ, E. J. \& ESTECONDO, S. 2008. Histological remarks of the oviduct and the oviducal gland of Sympterygia acuta (Garman, 1877). Braz. J. Biol., 68(2): 359-365.

GALINDEZ, E. J., DÍAZ-ANDRADE, M. C., AVACA, M. S. \& ESTECONDO, S. 2010. Morphological study of the oviductal gland in the smallnose fanskate Sympterygia bonapartii (Müller and Henle, 1841) (Chondrichthyes, Rajidae). Braz. J. Biol., 70(2): 325-333.

GILBERT, A. B., REYNOLDS, M. E. \& LORENZ, F. W. 1968. Distribution of spermatozoa in the oviduct and fertility in domestics hen.: histochemistry of the uterovaginal sperm hosts glands of the domestic hen. J. Reprod. Fertil., 16: 433-444.

Guia Brasileiro de Boas Práticas em Eutanásia em Animais - Conceitos e Procedimentos Recomendados. 2013. Editado pela Comissão de Ética, Bioética e Bem-Estar Animal/CFMV. Brasília. 62p.

HADDOCK, N. H. 1948. Alcian blue, a new phthalocyanin dyestuff. Research, 1(15): 685-689.

HAMLETT, W. C. 1999. Sharks, Skates, and Rays: The Biology of Elasmobranch Fishes. Baltimore, The Johns Hopkins University Press. $515 \mathrm{p}$.

HAMLETT, W. C. \& KOOB, T. J. 1999. Female reproductive system. In HAMLETT, W. C. (ed.). Sharks, Skates, and Rays: The Biology of Elasmobranch Fishes. The Johns Hopkins University Press, Baltimore, chap.15: 398 443.

HAMLETT, W. C., KNIGHT, D. P., JEZIOR, M., KAMM, K. \& MITCHELL, K. 1996. Ultras- 
tructure of the oviducal gland in the yellow spotted ray, Urolophus jamaicensis. Summer Meeting of the Anatomical Society of Great Britain and Ireland, Belfast, Northern Ireland. J. Anat., 188: 224-245.

HAMLETT, W. C., KNIGHT, D. P., KOOB, T. J., JEZIOR, M., LUONG, T., ROZYCKI, T., BRUNETTE, N. \& HYSELL, M. K. 1998a. Survey of oviducal gland structure and function in elasmobranchs. J. Exp. Zool., 282: 399-420.

HAMLETT, W. C., HYSELL, M. K., GALVIN, J. \& SPIELER, R. 1998b. Reproductive accommodations for gestation in the Atlantic guitarfish, Rhinobatos lentiginosus. J. Elisha Mitch. Sci. S. 114 (4): 199-208.

HAMLETT, W. C., HYSELL, M., JEZIOR, M., ROZYCKI, T., BRUNETTE, N. \& TUMILTY, K. 1999a. Fundamental zonation in elasmobranch oviducal glands. In SÉRET, B. \& SIRE, J.Y. (eds.). Proc. 5th Indo-Pac. Fish Conf., Nouméa, 1997. Soc. Fr. Ichtyol., Paris: 271-280.

HAMLETT, W. C., JEZIOR, M. \& SPIELER R. 1999b. Ultrastructural analysis of folliculogenesis in the ovary of the yellow spotted stingray, Urolophus jamaicensis. Ann. Anat., $181: 159-172$.

HAMLETT, W. C., MUSICK, J. A., HYSELL, C. K. \& SEVER, D. M. 2002a. Uterine epithelialsperm interaction, endometrial cycle and sperm storage in the terminal zone of the oviducal gland in the placental smoothound, Mustelus canis. J. Exp. Zool., 292: 129 - 144.

HAMLETT, W. C., FISHELSON, L., BARANES, A., HYSELL, C. K. \& SEVER, D.M. 2002b. Ultrastructural analysis of sperm storage and morphology of the oviducal gland in the Oman shark, Iago omanensis (Triakidae). Mar. Freshwater Res., 53, 601-613.

HAMLETT, W. C., KNIGHT, D. P., PEREIRA, F. T. V., STEELE, J. \& SEVER, D. M. 2005. Oviducal glands in Chondrichthyans. In HAMLETT, W.C. (ed.). Reproductive Biology and Phylogeny of Chondrichthyes: Sharks, Batoids and Chimaeras. Science Publishers, Enfield, :301-335.

HAZIN, F.H.V. 1991. Ecology of the blue shark, Prionace glauca, in the southwestern equatorial Atlantic Ocean. Tokyo. 123p. (M.Sc. Dis- sertation. Tokyo University of Fisheries, Department of Marine Science and Technology, Laboratory of Fisheries Oceanography).

HOLT, W. V. \& LLOYD, R. E. 2010. Sperm storage in the vertebrate female reproductive tract: How does it work so well? Theriogenology, 73:713-722.

KNIGHT, D. P., FENG, D., STEWART, M. \& KING, E. 1993. Changes in macromolecular organization in collagen assemblies during secretion in the nidamental gland and formation of the egg capsule wall in the dogfish Scyliorhinus canicula. Philos. T. Roy. Soc. Lon. B, 341: 419-436.

KNIGHT, D. P., FENG, D. \& STEWART, M. 1996. Structure and function of the selachian egg case. Biol. Rev., 71: 81- 111.

KOOB, T. J. \& CALLARD, I. P. 1991. Reproduction in female elasmobranchs. In KINNE, R. K. H. (ed.). Comparative Physiology: Oogenesis, Spermatogenesis and Reproduction. Basel, Karger, vol. 10: 155 - 209.

KOOB, T. J. \& STRAUS, J. W. 1998. On the role of egg jelly in Raja erinacea. Bulletin of the Mt. Desert Island Biological Laboratory 37: 117119.

LA MARCA, M. J. 1961. The anatomy of the reproductive system of the yellow stingray, Urolophus jamaicensis Cuvier. (Ph.D. Dissertation. Cornell University, Ithaca, New York, USA).

MAGNUSSON, W. E. 1979. Production of an embryo by an Acrochordus javanicus isolated for 7 years. Copeia, :744-745.

MALECKI, I. A., CLOETE, S. W. P, GERTENBACH, W. D. \& MARTINS, G. B. 2004. Sperm storage and duration of fertility in female ostriches (Struthio camelus). S. Afr. J. Anim. Sci., 34:158-165.

MATTEWS, L. H. 1950. Reproduction in the basking shark, Cetorhinus maximus (Gunner). Philos. T. Roy. Soc. B, 234: 247-316.

McMANUS, J. 1946. Histological Demonstration of Mucin after Periodic Acid. Nature, 158: 202.

McMILLAN, D.B. 2007. Fish Histology. Female Reproductive Systems. The Netherlands, 
Springer. 598 p.

METTEN, H. 1939. Studies on the reproduction of the dogfish. Philos. T. Roy. Soc. B, 230: 217 -238 .

MOURA, T., SERRA-PEREIRA, B., GORDO, L. S. \& FIGUEIREDO, I. 2011. Sperm storage in males and females of the deepwater shark Portuguese dogfish with notes on oviducal gland microscopic organization. J. Zool., 283: 210-219.

NALINI, K. P. 1940. Structure and function of the nidamental gland of Chiloscyllium griseum (Mull. and Henle). P. Indian Acad. Sci., 128: 189-214.

PORCU, C., MARONGIU, M. F., FOLLESA, M. C., BELLODI, A., MULAS, A., PESCI, P. \& CAU, A. 2015. Reproductive aspects of the velvet belly Etmopterus spinax (Chondrichthyes: Etmopteridae), from the central western Mediterranean Sea. Notes on gametogenesis and oviducal gland microstructure. Medit. Mar. Sci., 15(2): 313-326.

PRASAD, R. R. 1944. The structure, phylogenetic significance and function of the nidamental glands of some elasmobranchs of the Madras coast. P. Natl. Institute Sci. India, 11: 282302.

PRASAD, R. R. 1945. Further observations on the structure and function of the nidamental glands of a few elasmobranchs of the Madras coast. P. Indian Acad. Sci., 22: 368 - 373.

PRASAD, R. R. 1948. Observations on the nidamental glands of Hydrolagus colliei, Raja rhina and Platyrhinoids triseriatus. Copeia, : 54 -57 .

PRATT, H. L., Jr. 1979. Reproduction in the blue shark, Prionace glauca. U.S. Fish. Bull., 77:445-470.

PRATT, H.L., Jr. 1993. The storage of spermatozoa in the oviducal glands of western North Atlantic sharks. Env. Biol. Fish., 38: 139-149.

RACEY, P. A., UCHIDA, T. A., MORI, T., AVERY, M. I. \& FENTON, M. B. 1987. Spermepithelium relationships in relation to the time of insemination in little brown bats (Myotis lucifugus). J. Reprod. Fertil., 80:445-54.

RANGEL, B. S., BRUNO, C. E. M., SALMON, T.,
CIENA, A. P., MiglinO, M. A., AMORIM, A. F. \& RICI, R. E. G. 2015. Morphological analysis of the oviduct, oviducal gland and isthmus of the blue shark Prionace glauca (Linnaeus, 1758) (Elasmobranchii: Carcharhiniformes). Neotrop. Ichthyol., 13 (4):663-672.

ROSS, M. H., REITH, E. J. \& ROMRELL, L. J. 1993. Histologia: texto e atlas. São Paulo, Panamericana. $779 \mathrm{p}$.

RUSAOUËN, M. 1976. The dogfish shell gland, a histochemical study. J. Exp. Mar. Biol. Ecol., 23:267-283.

SALES, G., GIFFONI, B .B., FIEDLER, F. N., AZEVEDO, V. G., KOTAS, J. E., SWIMMER, Y. \& BUGONI, L. 2010. Circle hook effectiveness for the mitigation of sea turtle bycatch and capture of target species in a Brazilian pelagic longline fishery. Mar. Freshw. Ecosyst., 20: 428-436.

SERRA-PEREIRA, B., AFONSO, F., FARIAS, I., JOYCE, P., ELLIS, M., FIGUEIREDO, I. \& GORDO, L. S. 2011. The development of the oviducal gland in the Rajid thornback Ray, Raja clavata. Helgoland Mar. Res., 65:399411.

SMITH, R. M., WALKER, T. I. \& HAMLETT, W. C. 2004. Microscopic organization of the oviducal gland of the holocephalan elephant fish, Callorhynchus millii. Mar. Freshwater Res., 55 (2): 155-164.

SPIELER, R. E., FAHY, D. P., SHERMAN, R. L., SULIKOWSKI, J. A., \& QUINN, T. P. 2013. The yellow Stingray, Urobatis jamaicensis (Chondrichthyes: Urotrygonidae): a synoptic review. Caribb. J. Sci., 47, (1): 67-97.

STANLEY, H. P. 1963. Urogenital morphology in the chimaeroid fish Hydrolagus colliei (Lay and Bennett). J. Morphol., 112: 99 - 125.

STEVENS, J. D. 1974. The occurrence and significance of tooth cuts on the blue shark (Prionace glauca L.) from British waters. J. Mar. Biol. Assoc. U. K., 54: 373-378.

STORRIE, M. T., WALKER, T. I., LAURENSON, L., \& HAMLETT, W. C. 2001. Aplacental yolk sac viviparity in the gummy shark, Mustelus antarcticus. Six Indo-Pacific Fish Conference Scientific Programme and Book of Abstracts, 
20-25 May 2001, Durban, Oceanographic Research Institute. 59p.

STORRIE, M. T., WALKER, T. I., LAURENSON, L. J. \& HAMLETT, W. C. 2008. Microscopic organization of the sperm storage tubules in the oviducal gland of the female gummy shark (Mustelus antarcticus), with observations on sperm distribution and storage. J. Morphol., 269: 1308-1324.

STOWARD, P. J. 1967. The histochemical properties of some periodate-reactive mucosubstances of the pregnant Syrian hamster before and after methylation with methanolic thionyl chloride. Journal of the Royal Microscopical Society, 87(1): 77-103.

THREADGOLD, L. T. 1957. A histochemical study of the shell gland of Scyliorhinus caniculus. J. Histochem. Cytochem., 5: 159-166.

VILA, S., SÀBAT, M., HERNANDEZ, M. R. \& MUÑOZ, M. 2007. Intraovarian sperm storage in Helicolenus dactylopterus dactylopterus: fertilization, crypt formation and maintenance of stored sperm. Raffles B. Zool., 14:21 -7 . 